\title{
Plantas medicinais utilizadas na Comunidade Santo Antônio, Currais, Sul do Piauí: um enfoque etnobotânico
}

BAPTISTEL, A.C.; COUTINHO, J.M.C.P.; LINS NETO, E.M.F.; MONTEIRO, J.M.*

Departamento de Biologia, Universidade Federal do Piauí, Campus Profa. Cinobelina Elvas, BR 135, CEP: 64900-000, Bom Jesus, Piauí, Brasil. *Email: juliommonteiro@ufpi.edu.br

\begin{abstract}
RESUMO: O trabalho objetivou a realização de inventário sobre as plantas medicinais utilizadas pelos membros da Comunidade Rural de Santo Antônio, Currais, Piauí, e dessa forma analisar o valor de uso e a riqueza de espécies conhecidas. Foram mencionadas 121 espécies pelos 32 entrevistados. As famílias mais representativas foram Fabaceae, Arecaceae e Anacardiaceae. A espécie com maior valor de uso foi a imburana [Amburana cearensis (Allemao) A. C. Sm]. Não houve diferenças significativas quanto ao conhecimento entre gêneros, assim como a renda $e$ escolaridade. No entanto, a idade influenciou significativamente no conhecimento sobre plantas úteis. A riqueza da flora piauiense, marcada por apresentar áreas de transição entre caatinga e cerrado na região sul, oferece uma oportunidade ímpar para o desenvolvimento de pesquisas abrangendo o escopo da biodiversidade vegetal e do conhecimento tradicional associado.
\end{abstract}

Palavras-chave: Etnobotânica, Valor de uso, Fitoterapia, Conservação.

ABSTRACT: Medicinal plants used in the Community Santo Antônio, city of Currais, Southern Piauí, Brazil: an ethnobotanical approach. The study aimed toflist the medicinal plants used by members of the Rural Community of Santo Antonio, in the city of Currais, state of Piauí, Brazil, in order to assess the value of use and richness of the species known locally. Approximately 121 species were mentioned by 32 respondents. The most representative families were Fabaceae, Arecaceae and Anacardiaceae. The species with the highest use wa:[Amburana cearensis (Allemão) A. C. S]. There were no significant differences between genders in terms of knowledge, as well as income and education. However, the age significantly influenced knowledge about useful plants. The richness of the Piauí flora, marked by presenting areas of transition between the Brazilian Caatinga and Cerrado in the south, offers a unique opportunity for the development of research covering the scope of plant biodiversity and associated traditional knowledge.

Keywords: Ethnobotany, Value of Use, Phytotherapy, Conservation.

\section{INTRODUÇÃO}

Pesquisas no campo da etnobotânica têm fornecido valiosas informações sobre a forma de apropriação e manejo dos recursos vegetais por populações locais (Albuquerque, 2005). De modo geral, essas populações locais possuem um amplo conhecimento sobre métodos alternativos usados para curar ou aliviar sintomas de doenças. Porém, alguns autores argumentam que este conjunto de saberes está ameaçado pela medicina moderna e pelo crescente desinteresse dos jovens que tem migrado para os centros urbanos cada vez mais cedo em busca de novas conquistas profissionais (Franco \& Barros, 2006; Oliveira, 2009; Sousa, 2010).
Os estudos etnobotânicos no Brasil têm crescido atualmente, sobretudo enfocando plantas medicinais, e a região nordeste tem merecido destaque no cenário nacional (Albuquerque \& Andrade,1998; Monteiro et al., 2006; Araujo et al., 2008; Albuquerque et al., 2009; Silva et al., 2011; Souza et al., 2012). Alguns trabalhos enfocaram gêneros ou até espécies, dada a sua importância medicinal, religiosa e econômica local. Albuquerque \& Andrade (1998) realizaram pesquisa das espécies do gênero Ocimum, pertencente à família Lamiaceae, levantando seus dados morfológicos, botânicos, econômicos, seu uso místico-religioso no candomblé, sua entrada no Brasil e seu uso na 
África, observando assim, a existência simultânea desse gênero entre a cultura brasileira e africana. Monteiro et al. (2011), através de técnicas oriundas da economia ambiental, valoraram a aroeira do sertão (Myracrodruon urundeuva Allemao) e, com base nos resultados, estabeleceram que a planta apresenta uma larga importância local e pode ser alvo de propostas conservacionistas financiada pela sociedade. No Piauí, na Área de Proteção Ambiental (APA) do Delta do Parnaíba, Souza et al., (2012) encontraram, em pesquisas com comunidades de pescadores, que há grande conhecimento e uso da vegetação e mesmo com a crescente urbanização ainda há dependência da biodiversidade local.

Dessa forma, mesmo com o crescimento de pesquisas no Nordeste, ainda existem lacunas, principalmente para o estado do Piauí, cujos estudos etnobotânicos são escassos e o componente vegetacional ainda está pouco amostrado. Registram-se aqui os trabalhos de Emperaire (1989) e Lemos \& Rodal (2002) que estudaram o componente vegetacional da Serra da Capivara (Sul do Piauí) e perceberam que a vegetação é marcada pela transição entre a caatinga e o cerrado, evidenciando a riqueza da flora piauiense. Em outro trabalho importante para a região, o Programa de Pesquisas Ecológicas de Longa Duração (PELD-Sítio 10), foi levantado e prospectado a biodiversidade remanescente em áreas de cerrado e ecótonos associados, representando grande parte dos cerrados setentrionais do Piauí (Castro et al., 2010).

Diante do exposto, o presente trabalho teve como objetivo a realização de um inventário dos recursos vegetais usados como terapêuticos, pelos membros da Comunidade Santo Antônio, Currais, Piauí, a fim de avaliar a riqueza de espécies conhecidas localmente. Mais especificamente, acessar informações sobre indicações terapêuticas, partes utilizadas e formas de preparo das plantas medicinais. Procurou-se também quantificar o conhecimento através do valor de uso e verificar a diversidade de espécies conhecidas localmente entre gênero, idade e renda dos informantes.

\section{MATERIAIS E MÉTODOS}

\section{Área de estudo}

A área de estudo deste trabalho é o Povoado Santo Antônio, anteriormente chamado de Boca da Caatinga, pertencente ao Município de Currais, Piauí, localizado ao sul do estado do Piauí, na região do Médio Gurguéia, limitando-se ao norte com o município de Palmeira, ao sul com o município de Bom Jesus, ao leste, com Santa Luz e ao oeste com Baixa Grande do Ribeiro. Distam 640 km da capital Teresina e com população aproximada de 4722 habitantes (IBGE, 2008). O clima nesta região é do tipo semiárido, apresentando durante o verão uma estação de seca bem definida, tendo como principal elemento influenciador, o mecanismo de circulação das massas de ar e no inverno chuvas concentradas. A vegetação é constituída por árvores e arbustos densos, baixos, retorcidos, de aspecto seco durante o verão, folhas pequenas e caducas, apresentando raízes profundas e grossas, características predominantes da caatinga (Emperaire, 1989; Rodal \& Sampaio, 2002).

O povoado Santo Antônio é formado por casas de barro e alvenaria, pequenos comércios, uma igreja, uma escola e um posto de saúde que se encontram desativados, dificultando a educação formal das crianças e o atendimento médico para as 34 famílias residentes no local. No entanto, contam com uma equipe do Programa Saúde Familiar (PSF), que realiza visitas uma vez por mês na comunidade, encaminhando os casos mais graves de saúde para o Município de Bom Jesus e posteriormente para a capital Teresina. Os moradores da comunidade são de origem rural, onde $90 \%$ das pessoas sobrevivem da produção agrícola e da Bolsa Família, programa criado pelo Governo Federal em 2003. Os outros $10 \%$ constituem-se em pequenos empresários e funcionários públicos na esfera municipal. Basicamente realizam o plantio, manutenção e colheita de milho, feijão, arroz, mandioca e algumas hortaliças que são vendidas nas feiras livres locais.

\section{Coleta de dados}

As coletas foram realizadas no período de abril de 2010 a maio de 2011 com ocorrência das estações seca e chuvosa, totalizando 45 dias de trabalho. A viagem de campo dividida (Titiev, 2000) permitiu o acréscimo de informações entre distintas épocas do ano bem como suplantar as deficiências das viagens anteriores. Iniciou-se com visitas informais ao povoado estabelecendo uma relação de confiança com os moradores e o reconhecimento da área de estudo. Por ser uma comunidade pequena, 34 famílias, todos os responsáveis pelas residências foram convidados a participar, totalizando 32 entrevistas, dois moradores declinaram da participação. Após breve explicação dos objetivos do trabalho, todos foram convidados e assinar o termo de consentimento livre e esclarecido. Posteriormente, o trabalho foi aprovado pelo Comitê de Ética em Pesquisa com Seres Humanos da UFPI (Resolução 196/96 do Conselho Nacional de Saúde). O acesso ao conhecimento local ocorreu por meio de entrevistas semi-estruturadas (Albuquerque et al., 2008), dividida em duas etapas: coleta de dados socioeconômicos dos entrevistados e do conhecimento sobre plantas medicinais, cujo principal

Rev. Bras. PI. Med., Campinas, v.16, n.2, supl. I, p.406-425, 2014. 
questionamento foi sobre as indicações medicinais das plantas, preparo, doses, modo de administração e coleta das partes das plantas utilizadas. Turnêsguiadas foram realizadas próximas às residências (quintais, áreas de matas vizinhas e margens de estradas) para coleta e registro fotográfico de todas as plantas inventariadas, com auxílio dos informantes, promovendo o reconhecimento e a validação dos vernáculos das espécies citadas (Albuquerque et al., 2008). As plantas coletadas foram herborizadas e depositadas no Laboratório de Botânica da Universidade Federal do Piauí (Campus Profa. Cinobelina Elvas). O sistema APG III (Bremer, 2009) foi utilizado para a classificação das espécies e a verificação da nomenclatura científica foi conferida através do sítio eletrônico do Missouri Botanical Garden (MOBOT, 2011). Quanto ao status das espécies, consideraramse aqui plantas espontâneas ou cultivadas, de acordo com a proposta de Albuquerque et al. (2007a): as plantas que ocorrem naturalmente no ambiente e são recolhidas da vegetação local, sem serem cultivadas, foram classificadas como espontâneas. Também foram inseridas na categoria espontânea as espécies endêmicas da caatinga (Giulietti et al., 2002; Albuquerque et al., 2007a). Espécies cultivadas foram reconhecidas como não disponíveis na vegetação natural, sendo necessariamente manejadas e mantidas pela ação humana intencional.

A classificação das indicações de usos das plantas foi realizada através do Sistema de Classificação Estatística Internacional de Doenças e Problemas Relacionados à Saúde (WHO, 2007), proposta pela Organização Mundial da Saúde (OMS). As plantas medicinais indicadas para outras finalidades, tais como 'mau olhado' ou 'olho gordo' foram agrupadas na categoria "doenças culturais" (Giraldi \& Hanazaki, 2010).

\section{Análise dos dados}

Para análise dos dados obtidos através de uma única entrevista por informante foi calculado o valor de uso (VU) de cada espécie citada utilizando a fórmula adaptada por Rossato et al. (1999), cujo VU corresponde: $\Sigma U$ (somatório das citações para cada espécie) dividido por $n$ (número total de informantes).

Teste de variância Anova (um fator) foi utilizado para obter as diferenças entre a quantidade de plantas citadas e o gênero, e Kruskal-Wallis para comparar a existência de distinção do grau de estudo entre os gêneros (Ayres et al., 2007). Também se empregou teste de correlação de Spearman e regressão linear múltipla para verificação da relação entre valor de uso com idade, gênero, escolaridade e renda (Ayres et al., 2007).
Para estimar a riqueza de espécies citadas aplicou-se os seguintes estimadores: Chao de segunda ordem, Jacknife de primeira ordem e bootstrap, calculados através do EstimateS, versão 8.2 (Colwell, 2009). No sentido de evitar vieses devido a variação na abundância entre as plantas citadas, empregou-se análise de rarefação. Para as análises de diversidade empregou-se software ECOSIM 7 (Gotelli \& Entsminger, 2009) e para as estimativas de riqueza empregou-se Estimates 8. 2 (Colwell, 2009).

\section{RESULTADOS}

\section{Diversidade e valor de uso de plantas medicinais na Comunidade Santo Antonio, Currais, Piauí}

Foram citadas através das entrevistas 121 plantas com potencial medicinal, correspondendo a 118 espécies e 108 gêneros, distribuídas em 54 famílias (Tabela 1). As famílias mais representativas foram: Fabaceae (25 espécies), Arecaceae (08), Anacardiaceae (06), Asteraceae, Euphorbiaceae, Malvaceae e Rutaceae (05), Apocynaceae e Lamiaceae (04). Em relação às espécies utilizadas na fitoterapia tradicional foi observado que 15 se destacaram por apresentarem maior número de indicações (Tabela 1). São elas: imburana [Amburana cearensis (Allemao) A. C. Sm], erva cidreira [Lippia alba (Mill) N. E. Brown], batata de purga (Operculina sp.), mangabeira (Lafoensia replicata Pohl.), alecrim de chapada (Lippia gracillis H.B.K.), laranja [Citrus sinensis (L.) Osbeck], mastruz (Chenopodium ambrosioides L.) aroeira (Myracroduon urundeuva Allemão), hortelã (Mentha crispa L.), catinga de porco (Terminalia brasiliensis Camb), pau de rato (Caesalpinia bracteosa Tul.), jatobá (Hymenaea stigonocarpa var. pubescens Benth), boldo rasteiro [Plectranthus ornatos (Lour.) Spreng.], pau d'óleo (Copaifera langsdorffii Desf.) e inharé (Brosimum gaudichaudii Trecul.). Destas supracitadas, oito são elementos arbóreos encontrados na vegetação nativa. Um total de 77 plantas foi considerado espontâneo e 43 foram cultivadas. Tais resultados sinalizam a importância da vegetação nativa para a população local. Ainda com relação ao hábito, as plantas mencionadas, na sua maioria, foram: arbóreo (56\%), seguido do hábito herbáceo $(29 \%)$, arbusto (6\%), trepador/epifítico (5\%) e subarbusto (4\%) (Tabela 1).

As folhas foram as partes mais citadas $(28 \%)$, seguidas de frutos $(20 \%)$, casca e entrecasca $(18 \%)$, raiz $(11 \%)$, sementes $(8 \%)$. Outras partes foram apontadas totalizando $15 \%$ de todas as citações para partes usadas (exsudado, flores, inflorescências, planta inteira, bulbos, óleos, azeite

Rev. Bras. PI. Med., Campinas, v.16, n.2, supl. I, p.406-425, 2014. 
e látex). A forma de uso mais comum dos remédios caseiros foi por via oral e seu modo de preparo foi o chá (38\%) em decocção ou infusão, garrafadas (25\%) preparadas da extração da casca e entre casca das plantas arbóreas em solução com água, pó (15\%) feito a partir da raiz tuberosa e mucilagem, xaropes $(05 \%)$ confeccionados com mel de abelha. No uso de tratamento externo destacaram-se os emplastros (10\%) feitos da maceração de ervas e banhos $(03 \%)$ para aliviar as dores no corpo

TABELA 1. Lista de plantas medicinais citadas pela Comunidade Santo Antônio, Currais, PI. Legenda: ARB = arbóreo, ARS = arbusto, SUB = subarbusto, TRE = trepadeira, HEB = herbácea.

\begin{tabular}{|c|c|c|c|c|c|}
\hline $\begin{array}{l}\text { Família / } \\
\text { Espécie }\end{array}$ & $\begin{array}{l}\text { Nome(s) } \\
\text { popular(es) }\end{array}$ & $\begin{array}{l}\text { Hábito } \\
\text { (Status) }\end{array}$ & $\begin{array}{l}\text { Valor } \\
\text { de Uso }\end{array}$ & $\begin{array}{l}\text { Partes } \\
\text { usadas }\end{array}$ & Indicações \\
\hline \multicolumn{6}{|l|}{ Acanthaceae } \\
\hline $\begin{array}{l}\text { Justicia pectoralis var. } \\
\text { stenophylla Leonard }\end{array}$ & Anador & $\begin{array}{l}\text { HER } \\
\text { (cultivada) }\end{array}$ & 0,18 & Folhas & Febre, gripe, cólicas intestinais. \\
\hline \multicolumn{6}{|l|}{ Alliaceae } \\
\hline $\begin{array}{l}\text { Nothoscordum striatum } \\
\text { Jacq. }\end{array}$ & Alho bravo & $\begin{array}{l}\text { HER } \\
\text { (espontânea) }\end{array}$ & 0,06 & Folhas & Hipertensão, gripe. \\
\hline \multicolumn{6}{|l|}{ Amaranthaceae } \\
\hline $\begin{array}{l}\text { Alternanthera } \\
\text { brasiliana (L.) O. Kunt }\end{array}$ & Doril & $\begin{array}{l}\text { HER } \\
\text { (Sem dados) }\end{array}$ & 0,09 & Folhas & Febre, gripe, cólicas abdominais. \\
\hline \multicolumn{6}{|l|}{ Anacardiaceae } \\
\hline $\begin{array}{l}\text { Anacardium } \\
\text { occidentale L. }\end{array}$ & Caju & $\begin{array}{l}\text { ARB } \\
\text { (espontânea) }\end{array}$ & 0,43 & Folhas & $\begin{array}{l}\text { Febre, gripe, cefaleia, dor de dente, ressaca, } \\
\text { ferimento. }\end{array}$ \\
\hline $\begin{array}{l}\text { Astronium fraxinifolium } \\
\text { Schott ex Spreng }\end{array}$ & Gonçalado & $\begin{array}{l}\text { ARB } \\
\text { (espontânea) }\end{array}$ & 0,06 & Cascas & Dor de estômago e infecção renal. \\
\hline Mangifera indica L. & Manga & $\begin{array}{l}\text { ARB } \\
\text { (cultivada) }\end{array}$ & 0,12 & Folhas & Inflamação dos dentes. \\
\hline $\begin{array}{l}\text { Myracrodruon } \\
\text { urundeuva Allemão }\end{array}$ & Aroeira & $\begin{array}{l}\text { ARB } \\
\text { (espontânea) }\end{array}$ & 0,87 & Cascas & $\begin{array}{l}\text { Infecção do aparelho geniturinário feminino e } \\
\text { masculino, cicatrização, fratura, infecção renal e } \\
\text { urinário, diarreia, anemia, dor no corpo, infecção } \\
\text { no ouvido, cólicas intestinais, dor no estômago } \\
\text { e depurativo. }\end{array}$ \\
\hline Spondias mombin L. & Cajá & $\begin{array}{l}\text { ARB } \\
\text { (espontânea) }\end{array}$ & 0,12 & Cascas & $\begin{array}{l}\text { Neoplasia, dor de estômago, regulador intestinal, } \\
\text { pós-operatório. }\end{array}$ \\
\hline Spondias purpurea L. & Seriguela & $\begin{array}{l}\text { ARB } \\
\text { (espontânea) }\end{array}$ & 0,06 & Cascas & Gripe, febre. \\
\hline \multicolumn{6}{|l|}{ Annonaceae } \\
\hline Annona squamosa L. & Ata & $\begin{array}{l}\text { ARB } \\
\text { (cultivada) }\end{array}$ & 0,06 & Folhas & Dor de estômago e febre. \\
\hline
\end{tabular}


TABELA 1. Lista de plantas medicinais citadas pela Comunidade Santo Antônio, Currais, PI. Legenda: ARB = arbóreo, ARS = arbusto, SUB = subarbusto, TRE = trepadeira, HEB = herbácea.

\section{Apiaceae}

\begin{tabular}{|l|l|l|l|l|l|}
\hline Coriandrum sativum L. & Coentro & $\begin{array}{l}\text { HER } \\
\text { (cultivada) }\end{array}$ & 0.03 & Folhas & Gripe. \\
\hline Pimpinella anisum L. & Erva Doce & $\begin{array}{l}\text { HER } \\
\text { (cultivada) }\end{array}$ & 0,06 & Folhas & Febre. \\
\hline
\end{tabular}

\section{Apocynaceae}

\begin{tabular}{|l|l|l|l|l|l|}
\hline $\begin{array}{l}\text { Anisolobus cururu } \\
\text { Müll. Arg. }\end{array}$ & Cipó Cururu & $\begin{array}{l}\text { TER } \\
\text { (espontânea) }\end{array}$ & 0,03 & Látex & Luxação. \\
\hline $\begin{array}{l}\text { Peschiera fuchsiaefolia } \\
\text { (A. DC.) Miers }\end{array}$ & Pau leiteiro & $\begin{array}{l}\text { ARB } \\
\text { (espontânea) }\end{array}$ & 0,03 & Látex & Gripe. \\
\hline
\end{tabular}

\begin{tabular}{|l|l|l|l|l|l|}
\hline \multicolumn{2}{|l|}{ Arecaceae } \\
$\begin{array}{l}\text { Copernicia prunifera } \\
\text { (Miller) H. E. Moore }\end{array}$ & Carnaúba & $\begin{array}{l}\text { ARB } \\
\text { (espontânea) }\end{array}$ & 0,09 & Raiz & Coluna, infecção renal. \\
\hline Mauritia flexuosa L. & Buriti & $\begin{array}{l}\text { ARB } \\
\text { (espontânea) }\end{array}$ & 0,12 & $\begin{array}{l}\text { Folhas; } \\
\text { óleo }\end{array}$ & Picada de cobra e insetos, queimadura. \\
\hline $\begin{array}{l}\text { Orbignya phalerata } \\
\text { Mart }\end{array}$ & Babaçu & $\begin{array}{l}\text { ARB } \\
\text { (espontânea) }\end{array}$ & 0,15 & $\begin{array}{l}\text { Frutas; } \\
\text { folhas }\end{array}$ & Picada de cobra, edema facial. \\
\hline Syagrus sp. & Pati & $\begin{array}{l}\text { ARB } \\
\text { (espontânea) }\end{array}$ & 0,03 & $\begin{array}{l}\text { Frutas; } \\
\text { folhas }\end{array}$ & Asma. \\
\hline
\end{tabular}

\section{Asphodelaceae}

\begin{tabular}{|l|l|l|l|l|l|}
\hline Aloe vera Mills. & Babosa & $\begin{array}{l}\text { HER } \\
\text { (cultivada) }\end{array}$ & 0,34 & $\begin{array}{l}\text { Folhas; } \\
\text { mucilagem }\end{array}$ & Neoplasia, anemia, gripe, coceira. \\
\hline
\end{tabular}

\section{Asteraceae}

\begin{tabular}{|l|l|l|l|l|l|}
\hline $\begin{array}{l}\text { Egletes viscosa (L.) } \\
\text { Less. }\end{array}$ & Macela & $\begin{array}{l}\text { HER } \\
\text { (espontânea) }\end{array}$ & 0,12 & $\begin{array}{l}\text { Folhas; } \\
\text { flores }\end{array}$ & $\begin{array}{l}\text { Derrame, epilepsia, lavagem intestinal e } \\
\text { estomacal. }\end{array}$ \\
\hline Bidens pilosa L. & Picão & $\begin{array}{l}\text { SUB } \\
\text { (espontânea) }\end{array}$ & 0,03 & Folhas; raiz & Amarelão, \\
\hline $\begin{array}{l}\text { Gochnatia polymorpha } \\
\text { (Less) Cabrera }\end{array}$ & Candeia & $\begin{array}{l}\text { ARB } \\
\text { (espontânea) }\end{array}$ & 0,03 & Cascas & Infecção do ap. geniturinário feminino. \\
\hline $\begin{array}{l}\text { Vernonia condensata } \\
\text { Baker }\end{array}$ & Boldo baiano & $\begin{array}{l}\text { SUB } \\
\text { (espontânea) }\end{array}$ & 0,06 & Folhas & Dor no fígado. \\
\hline $\begin{array}{l}\text { Vernonia polysphaera } \\
\text { Less }\end{array}$ & Assa peixe & $\begin{array}{l}\text { ARS } \\
\text { (espontânea) }\end{array}$ & 0,18 & Folhas & Pneumonia, gripe forte, resfriado, algia. \\
\hline
\end{tabular}


TABELA 1. Lista de plantas medicinais citadas pela Comunidade Santo Antônio, Currais, PI. Legenda: $A R B=$ arbóreo, $A R S$ = arbusto, SUB = subarbusto, TRE = trepadeira, HEB = herbácea.

\section{Bignoniaceae}

\begin{tabular}{|l|l|l|l|l|l|}
\hline $\begin{array}{l}\text { Handroanthus aurea } \\
\text { (Silva Manso) Benth \& } \\
\text { Hook.ex S. Moore }\end{array}$ & $\begin{array}{l}\text { Pau D'arco } \\
\text { Amarelo }\end{array}$ & $\begin{array}{l}\text { ARB } \\
\text { (espontânea) }\end{array}$ & 0,03 & Cascas & Infecção no intestino. \\
\hline $\begin{array}{l}\text { Handroanthus } \\
\text { impetiginosa (Mart. Ex } \\
\text { DC.) Standl }\end{array}$ & $\begin{array}{l}\text { Pau D'arco } \\
\text { Roxo }\end{array}$ & $\begin{array}{l}\text { ARB } \\
\text { (espontânea) }\end{array}$ & 0,37 & Cascas & $\begin{array}{l}\text { Infecção do ap. geniturinário feminino, neoplasia, } \\
\text { o corpo, diabetes, gripe, gastrite, anemia, } \\
\text { infecção intestinal, fortificante, depurativo, dor } \\
\text { no estômago. }\end{array}$ \\
\hline Bixaceae & Urucum & $\begin{array}{l}\text { ARS } \\
\text { (cultivada) }\end{array}$ & 0,06 & Sementes & Colesterol, diabetes. \\
\hline $\begin{array}{l}\text { Bixa orellana L } \\
\text { Boraginaceae }\end{array}$ & $\begin{array}{l}\text { Crista de } \\
\text { galo }\end{array}$ & $\begin{array}{l}\text { HER } \\
\text { (espontânea) }\end{array}$ & $\begin{array}{l}0,34 \\
\text { Heliotropium } \\
\text { elongatum Lehm. I. M. } \\
\text { Johnst }\end{array}$ & $\begin{array}{l}\text { Folhas; } \\
\text { flores }\end{array}$ & Nascimento dos dentes, diarreia. \\
\hline
\end{tabular}

Brassicaceae

Brassica nigra L.

\begin{tabular}{|l|l|l|l|l} 
Mostarda & $\begin{array}{l}\text { HER } \\
\text { (cultivada) }\end{array}$ & 0,03 & Sementes & Derrame. \\
\hline
\end{tabular}

Bromeliaceae

\begin{tabular}{|l|l|l|l|l|l|}
\hline $\begin{array}{l}\text { Ananas comosus L. } \\
\text { Merr. }\end{array}$ & Abacaxi & $\begin{array}{l}\text { HER } \\
\text { (cultivada) }\end{array}$ & 0,03 & Frutas & Gripe. \\
\hline $\begin{array}{l}\text { Bromelia laciniosa } \\
\text { Mart. }\end{array}$ & Croatá & $\begin{array}{l}\text { HER } \\
\text { (espontânea) }\end{array}$ & 0,06 & Frutas & Pneumonia, gripe forte. \\
\hline
\end{tabular}

\section{Cactaceae}

\begin{tabular}{|l|l|l|l|l|l|}
\hline Cereus jamacaru DC. & Mandacaru & $\begin{array}{l}\text { HER } \\
\text { (espontânea) }\end{array}$ & 0,06 & Epiderme & Infecção do aparelho geniturinário feminino. \\
\hline $\begin{array}{l}\text { Opuntia cochenillifera } \\
\text { (L) Mill }\end{array}$ & Palma & $\begin{array}{l}\text { HER } \\
\text { (espontânea) }\end{array}$ & 0,06 & Cladódio & $\begin{array}{l}\text { Infecção do aparelho geniturinário masculino, } \\
\text { próstata. }\end{array}$ \\
\hline
\end{tabular}

\section{Caricaceae}

\begin{tabular}{|l|l|l|l|l|l|}
\hline Carica papaya L. & Mamão & $\begin{array}{l}\text { ARB } \\
\text { (cultivada) }\end{array}$ & 0,34 & $\begin{array}{l}\text { Folhas; } \\
\text { frutas }\end{array}$ & $\begin{array}{l}\text { Cólicas intestinais, gripe, mal estar, má digestão } \\
\text { e regulador intestinal. }\end{array}$ \\
\hline
\end{tabular}


TABELA 1. Lista de plantas medicinais citadas pela Comunidade Santo Antônio, Currais, PI. Legenda: ARB = arbóreo, ARS = arbusto, SUB = subarbusto, TRE = trepadeira, HEB = herbácea.

continua...

\begin{tabular}{|c|c|c|c|c|c|}
\hline \multicolumn{6}{|l|}{ Caryocaraceae } \\
\hline $\begin{array}{l}\text { Caryocar coriaceum } \\
\text { Wittm }\end{array}$ & Piquí & $\begin{array}{c}\text { ARB } \\
\text { (espontânea) }\end{array}$ & 0,03 & Óleo & Gripe. \\
\hline \multicolumn{6}{|l|}{ Chenopodiaceae } \\
\hline $\begin{array}{l}\text { Chenopodium } \\
\text { ambrosioides L. }\end{array}$ & Mastruz & $\begin{array}{l}\text { HER } \\
\text { (cultivada) }\end{array}$ & 1,00 & $\begin{array}{l}\text { Planta } \\
\text { inteira }\end{array}$ & $\begin{array}{l}\text { Cicatrização, pós-cirurgia, luxações, } \\
\text { machucados em geral, puerpério, vermes, } \\
\text { ferimentos inflamados, gastrite, fraturas, dor } \\
\text { no corpo, hematomas (pancadas), edema } \\
\text { localizado, sangue grosso, mal estar, fígado, } \\
\text { esfoliações. }\end{array}$ \\
\hline \multicolumn{6}{|l|}{ Combretaceae } \\
\hline $\begin{array}{l}\text { Combretum leprosum } \\
\text { Mart. }\end{array}$ & Bugio & $\begin{array}{l}\text { ARB } \\
\text { (espontânea) }\end{array}$ & 0,09 & $\begin{array}{l}\text { Folhas; } \\
\text { cascas }\end{array}$ & Tosse, diarreia \\
\hline $\begin{array}{l}\text { Terminalia glabrescens } \\
\text { Mart. }\end{array}$ & $\begin{array}{l}\text { Catinga de } \\
\text { Porco }\end{array}$ & $\begin{array}{l}\text { ARB } \\
\text { (espontânea) }\end{array}$ & 0,84 & Cascas & $\begin{array}{l}\text { Infecção do ap. geniturinário feminino, } \\
\text { diarreia, ferimentos, dor de estomago, má } \\
\text { digestão, gengivite, infecção intestinal, úlcera } \\
\text { no estomago, cólica intestinal, constipação. }\end{array}$ \\
\hline \multicolumn{6}{|l|}{ Convolvulaceae } \\
\hline Operculina sp. & $\begin{array}{l}\text { Batata de } \\
\text { Purga }\end{array}$ & $\begin{array}{l}\text { TER } \\
\text { (espontânea) }\end{array}$ & 1,40 & Raiz & $\begin{array}{l}\text { Complemento vitamínico, má digestão, dor } \\
\text { no estomago, vermífugo, gripe, depurativo, } \\
\text { constipação. }\end{array}$ \\
\hline $\begin{array}{l}\text { Ipomoea batatas }(\mathrm{L}) \\
\text { Lam. }\end{array}$ & Batata Doce & $\begin{array}{l}\text { TER } \\
\text { (cultivada) }\end{array}$ & 0,03 & Raiz & Dor de dente. \\
\hline \multicolumn{6}{|l|}{ Crassulaceae } \\
\hline $\begin{array}{l}\text { Kalanchoe pinnata } \\
\text { (Lam.) Pers. }\end{array}$ & Folha Santa & $\begin{array}{l}\text { HER } \\
\text { (cultivada) }\end{array}$ & 0,06 & Folhas & $\begin{array}{l}\text { Infecção por } \\
\text { fratura. }\end{array}$ \\
\hline \multicolumn{6}{|l|}{ Cucurbitaceae } \\
\hline Cucurbita pepo L & Abóbora & $\begin{array}{l}\text { TER } \\
\text { (cultivada) }\end{array}$ & 0,03 & Sementes & Gripe. \\
\hline \multicolumn{6}{|l|}{ Euphorbiaceae } \\
\hline $\begin{array}{l}\text { Cnidoscolus urens (L.) } \\
\text { Arthur }\end{array}$ & Cansanção & $\begin{array}{l}\text { ARS } \\
\text { (espontânea) }\end{array}$ & 0,06 & Folhas & Neoplasia \\
\hline $\begin{array}{l}\text { Croton rhamnifolius } \\
\text { Kunth. }\end{array}$ & Velame & $\begin{array}{l}\text { ARB } \\
\text { (espontânea) }\end{array}$ & 0,34 & Raiz & $\begin{array}{l}\text { Infecção do aparelho geniturinário feminino } \\
\text { e masculino, febre, diarréia, gripe, picada de } \\
\text { cobra. }\end{array}$ \\
\hline
\end{tabular}


TABELA 1. Lista de plantas medicinais citadas pela Comunidade Santo Antônio, Currais, PI. Legenda: $A R B=$ arbóreo, $A R S$ = arbusto, SUB = subarbusto, TRE = trepadeira, HEB = herbácea.

continua...

\begin{tabular}{|l|l|l|l|l|l|}
\hline Euphorbia tirucalli L. & $\begin{array}{l}\text { Cachorro } \\
\text { Pelado }\end{array}$ & $\begin{array}{l}\text { ARB } \\
\text { (cultivada) }\end{array}$ & 0,06 & Látex & Neoplasia. \\
\hline $\begin{array}{l}\text { Jatropha gossypiifolia } \\
\text { L. }\end{array}$ & Pinhão Roxo & $\begin{array}{l}\text { HER } \\
\text { (cultivada) }\end{array}$ & 0,03 & Sementes & Intestino. \\
\hline Phyllantus niruri L. & $\begin{array}{l}\text { Quebra- } \\
\text { Pedra }\end{array}$ & $\begin{array}{l}\text { HER } \\
\text { (espontânea) }\end{array}$ & 0,09 & $\begin{array}{l}\text { Planta } \\
\text { inteira; } \\
\text { folhas }\end{array}$ & Infecção renal, fígado. \\
\hline Ricinus communis L. & Mamona & $\begin{array}{l}\text { HER } \\
\text { (cultivada) }\end{array}$ & 0,06 & $\begin{array}{l}\text { Sementes } \\
\text { (óleo) }\end{array}$ & Cólicas abdominais, puerpério. \\
\hline
\end{tabular}

Fabaceae -Subfam Caesalpinioideae

\begin{tabular}{|c|c|c|c|c|c|}
\hline Bauhinia ungulata L. & Miroró & $\begin{array}{l}\text { ARB } \\
\text { (espontânea) }\end{array}$ & 0,03 & Cascas & Diarreia. \\
\hline Bauhinia dubia G. Don & Pata de Vaca & $\begin{array}{l}\text { ARB } \\
\text { (espontânea) }\end{array}$ & 0,03 & Cascas & Diabetes. \\
\hline $\begin{array}{l}\text { Caesalpinia bracteosa } \\
\text { Tul. }\end{array}$ & Pau de Rato & $\begin{array}{l}\text { ARB } \\
\text { (espontânea) }\end{array}$ & 0,81 & $\begin{array}{l}\text { Frutos; } \\
\text { cascas }\end{array}$ & $\begin{array}{l}\text { Infecção renal, fígado, gastrite, hipertensão, } \\
\text { diarreia, infecção intestinal de adulto e criança, } \\
\text { cólica intestinal, má digestão, auxilia no } \\
\text { nascimento dos dentes de criança. }\end{array}$ \\
\hline $\begin{array}{l}\text { Caesalpinia ferrea var. } \\
\text { leiostachya Benth }\end{array}$ & Pau Ferro & $\begin{array}{l}\text { ABR } \\
\text { (espontânea) }\end{array}$ & 0,43 & $\begin{array}{l}\text { Frutos; } \\
\text { cascas }\end{array}$ & Gripe, azia, fígado, machucados. \\
\hline $\begin{array}{l}\text { Cenostigma } \\
\text { macrophyllum } \\
\text { Tull }\end{array}$ & $\begin{array}{l}\text { Canela do } \\
\text { Cerrado }\end{array}$ & $\begin{array}{l}\text { ARB } \\
\text { (espontânea) }\end{array}$ & 0,09 & $\begin{array}{l}\text { Folhas; } \\
\text { cascas }\end{array}$ & Resfriados, febre, gripe forte. \\
\hline $\begin{array}{l}\text { Copaifera langsdorffii } \\
\text { Desf. }\end{array}$ & Pau D’óleo & $\begin{array}{l}\text { ARB } \\
\text { (espontânea) }\end{array}$ & 0,75 & Óleo & $\begin{array}{l}\text { Tosse, gripe, asma, doenças sexualmente } \\
\text { transmissíveis (DST), ferimentos, cicatrização, } \\
\text { inflamação da garganta, dor no corpo, gripe } \\
\text { crônica, epilepsia, enxaqueca, fratura da bacia. }\end{array}$ \\
\hline $\begin{array}{l}\text { Pterodon polygaliflorus } \\
\text { (Benth.) Benth. }\end{array}$ & $\begin{array}{l}\text { Birro } \\
\text { Cangalheiro }\end{array}$ & $\begin{array}{l}\text { ARB } \\
\text { (espontânea) }\end{array}$ & 0,12 & Cascas & $\begin{array}{l}\text { Depurativo, estimulante do apetite, coluna, } \\
\text { infecção renal. }\end{array}$ \\
\hline $\begin{array}{l}\text { Hymenaea } \\
\text { stigonocarpa var. } \\
\text { pubescens Benth. }\end{array}$ & Jatobá & $\begin{array}{l}\text { ARB } \\
\text { (espontânea) }\end{array}$ & 0,78 & Cascas & $\begin{array}{l}\text { Anemia, gripe, depurativo, regulação do } \\
\text { intestino, dor no corpo, cólica intestinal, úlcera } \\
\text { de estomago, conjuntivite, fortificante, má } \\
\text { digestão, infecção do ap. geniturinário feminino. }\end{array}$ \\
\hline $\begin{array}{l}\text { Senna obtusifolia (L.) } \\
\text { H. S. Irwin \& Barneby }\end{array}$ & Mata Pasto & $\begin{array}{l}\text { HEB } \\
\text { (espontânea) }\end{array}$ & 0,03 & Raiz & Psoríase \\
\hline $\begin{array}{l}\text { Senna occidentalis (L.) } \\
\text { Link }\end{array}$ & Fedegoso & $\begin{array}{l}\text { ARS } \\
\text { (espontânea) }\end{array}$ & 0,34 & Folhas & $\begin{array}{l}\text { Fígado estômago, abortivo, gripe, diarréia, } \\
\text { sarampo. }\end{array}$ \\
\hline
\end{tabular}


TABELA 1. Lista de plantas medicinais citadas pela Comunidade Santo Antônio, Currais, PI. Legenda: ARB = arbóreo, ARS = arbusto, SUB = subarbusto, TRE = trepadeira, HEB = herbácea.

continua...

\begin{tabular}{|l|l|l|l|l|l|}
\hline $\begin{array}{l}\text { Senna spectabilis var. } \\
\text { excelsa (Schrad.) H. S. } \\
\text { Irwin \& Barneby }\end{array}$ & Canafistula & $\begin{array}{l}\text { ARB } \\
\text { (espontânea) }\end{array}$ & 0,06 & Cascas & Hemorragia, ferimentos. \\
\hline Tamarindus indica L. & Tamarindo & $\begin{array}{l}\text { ARB } \\
\text { (cultivada) }\end{array}$ & 0,03 & Folhas & Gripe. \\
\hline
\end{tabular}

Fabaceae -Subfam. Faboideae

\begin{tabular}{|l|l|l|l|l|l|}
\hline $\begin{array}{l}\text { Amburana cearensis } \\
\text { (Allemao) A. C. Sm. }\end{array}$ & Imburana & $\begin{array}{l}\text { ARB } \\
\text { (espontânea) }\end{array}$ & 1,59 & $\begin{array}{l}\text { Cascas; } \\
\text { sementes }\end{array}$ & $\begin{array}{l}\text { Cólica intestinal, gripe, dor de estômago, } \\
\text { picada de cobra e lacraia, desidratação, } \\
\text { diarreia, enxaqueca, emese, dor de cabeça e } \\
\text { articulações, vertigem, febre, intestino preso, } \\
\text { depurativo, diurético, infecção renal. }\end{array}$ \\
\hline $\begin{array}{l}\text { Bowdichia virgilioides } \\
\text { Kunth }\end{array}$ & Sucupira & $\begin{array}{l}\text { ARB } \\
\text { (espontânea) }\end{array}$ & 0,06 & Sementes & Inflamação da garganta, coluna. \\
\hline $\begin{array}{l}\text { Dioclea violacea Mart } \\
\text { ex Benth }\end{array}$ & Mucunã & $\begin{array}{l}\text { TER } \\
\text { (espontânea) }\end{array}$ & 0,12 & Látex & Diarreia, depurativo, infecção renal \\
\hline $\begin{array}{l}\text { Dipteryx lacunifera } \\
\text { Ducke }\end{array}$ & $\begin{array}{l}\text { Fava de } \\
\text { Morcego }\end{array}$ & $\begin{array}{l}\text { ARB } \\
\text { (espontânea) }\end{array}$ & 0,06 & Frutos & Coluna \\
\hline
\end{tabular}

Fabaceae - Subfam. Mimosoideae

\begin{tabular}{|c|c|c|c|c|c|}
\hline $\begin{array}{l}\text { Anadenanthera } \\
\text { colubrina (Vell.) } \\
\text { Brenan }\end{array}$ & $\begin{array}{l}\text { Angico } \\
\text { branco }\end{array}$ & $\begin{array}{l}\text { ARB } \\
\text { (espontânea) }\end{array}$ & 0,03 & Cascas & Anemia. \\
\hline $\begin{array}{l}\text { Anadenathera falcata } \\
\text { (Benth.) Speg. }\end{array}$ & Angico & $\begin{array}{l}\text { ARB } \\
\text { (espontânea) }\end{array}$ & 0,68 & Cascas & $\begin{array}{l}\text { Depurativo, ferimento, gripe, tosse, queimadura, } \\
\text { furúnculo, } \\
\text { cólica intestinal. }\end{array}$ \\
\hline $\begin{array}{l}\text { Anadenanthera } \\
\text { macrocarpa (Benth.) } \\
\text { Brenan }\end{array}$ & Angico Preto & $\begin{array}{l}\text { ARB } \\
\text { (espontânea) }\end{array}$ & 0,03 & Cascas & Cólicas abdominais. \\
\hline $\begin{array}{l}\text { Brosimum } \\
\text { gaudichaudii Trécul. }\end{array}$ & Inharé & $\begin{array}{l}\text { ARB } \\
\text { (espontânea) }\end{array}$ & 0,65 & $\begin{array}{l}\text { Exsudato; } \\
\text { cascas; } \\
\text { frutos }\end{array}$ & $\begin{array}{l}\text { Fortificante, depurativo, afina o sangue, } \\
\text { ferimentos, neoplasia, inflamações, dor no } \\
\text { corpo, alergia de picada de mosquito, circulação } \\
\text { sanguínea. }\end{array}$ \\
\hline $\begin{array}{l}\text { Dimorphandra } \\
\text { gardneriana Tull. }\end{array}$ & Fava D'anta & $\begin{array}{l}\text { ARB } \\
\text { (espontânea) }\end{array}$ & 0,31 & Raiz & Cólicas intestinais, diarreia, coluna. \\
\hline $\begin{array}{l}\text { Mimosa verrucosa } \\
\text { Benth }\end{array}$ & $\begin{array}{l}\text { Jurema } \\
\text { Branca }\end{array}$ & $\begin{array}{l}\text { ARB } \\
\text { (espontânea) }\end{array}$ & 0,03 & Cascas & Inflamação renal. \\
\hline $\begin{array}{l}\text { Parkia platycephala } \\
\text { Benth. }\end{array}$ & $\begin{array}{l}\text { Fava de } \\
\text { Bolota }\end{array}$ & $\begin{array}{l}\text { ARB } \\
\text { (espontânea) }\end{array}$ & 0,18 & Cascas & Cólicas intestinais, diarreia, coluna. \\
\hline $\begin{array}{l}\text { Pithecollobium tortum } \\
\text { Mart. }\end{array}$ & Jurema Rosa & $\begin{array}{l}\text { ARB } \\
\text { (espontânea) }\end{array}$ & 0,09 & Cascas & Infecção intestinal, diarreia. \\
\hline
\end{tabular}


TABELA 1. Lista de plantas medicinais citadas pela Comunidade Santo Antônio, Currais, PI. Legenda: ARB = arbóreo, ARS = arbusto, SUB = subarbusto, TRE = trepadeira, HEB = herbácea.

continua...

\section{Flacourtiaceae}

\begin{tabular}{|l|l|l|l|l|l}
\hline $\begin{array}{l}\text { Casearia sylvestris var. } \\
\text { angustifolia Uittien }\end{array}$ & $\begin{array}{l}\text { Folha de } \\
\text { Carne }\end{array}$ & $\begin{array}{l}\text { ARB } \\
\text { (espontânea) }\end{array}$ & 0,53 & Folhas & Regulador intestinal, dor no estômago, gripe. \\
\hline
\end{tabular}

\section{Krameriaceae}

\begin{tabular}{|l|l|l|l|l|l}
\hline $\begin{array}{l}\text { Krameria argentea } \\
\text { Mart. Ex Spreng }\end{array}$ & $\begin{array}{l}\text { Carrapicho } \\
\text { de Boi }\end{array}$ & $\begin{array}{l}\text { SUB } \\
\text { (espontânea) }\end{array}$ & 0,03 & Raiz & Bursite. \\
\hline
\end{tabular}

\section{Lamiaceae}

\begin{tabular}{|l|l|l|l|l|l|}
\hline $\begin{array}{l}\text { Coleus amboinicus } \\
\text { Lour }\end{array}$ & Malvão & $\begin{array}{l}\text { SUB } \\
\text { (cultivada) }\end{array}$ & 0,50 & Folhas & $\begin{array}{l}\text { Febre, diarreia, cólica intestinal, gripe, dor de } \\
\text { garganta e ouvido, tosse. }\end{array}$ \\
\hline Mentha crispa L. & Hortelã & $\begin{array}{l}\text { HER } \\
\text { (cultivada) }\end{array}$ & 0,87 & Folhas & $\begin{array}{l}\text { Febre, cólicas intestinais, dor no corpo, gripe, } \\
\text { hipertensão, calmante, nascimento de dentes } \\
\text { da criança. }\end{array}$ \\
\hline $\begin{array}{l}\text { Plectranthus ornatus } \\
\text { (Lour.) Spreng. }\end{array}$ & $\begin{array}{l}\text { Boldo } \\
\text { Rasteiro }\end{array}$ & $\begin{array}{l}\text { SUB } \\
\text { (cultivada) }\end{array}$ & 0,75 & Folhas & $\begin{array}{l}\text { Má digestão, dor de estômago, } \\
\text { regulador intestinal, mal estar, fígado, ressaca, } \\
\text { cólicas intestinais, dor de cabeça e no corpo. }\end{array}$ \\
\hline Ocimum basilicum L. & Canelinha & $\begin{array}{l}\text { HER } \\
\text { (cultivada) }\end{array}$ & 0,12 & Folhas & $\begin{array}{l}\text { Obstrução nasal, gripe, dor no } \\
\text { corpo. }\end{array}$ \\
\hline
\end{tabular}

Lauraceae

\begin{tabular}{|l|l|l|l|l|l|}
\hline Persea americana Mill & Abacate & $\begin{array}{l}\text { ARB } \\
\text { (cultivada) }\end{array}$ & 0,03 & $\begin{array}{l}\text { Mesocarpo; } \\
\text { caroço }\end{array}$ & Infecção renal. \\
\hline
\end{tabular}

Liliaceae

\begin{tabular}{|l|l|l|l|l|l}
\hline Allium sativum $\mathrm{L}$ & Alho & $\begin{array}{l}\text { HER } \\
\text { (cultivada) }\end{array}$ & 0,09 & Bulbo & Gripe, hipertensão. \\
\hline
\end{tabular}

Lecythidaceae

\begin{tabular}{|c|c|c|c|c|c|}
\hline $\begin{array}{l}\text { Lecythis pisonis } \\
\text { Cambess }\end{array}$ & Sapucaia & $\begin{array}{l}\text { ARB } \\
\text { (espontânea) }\end{array}$ & 0,03 & Cascas & Diabetes. \\
\hline \multicolumn{6}{|l|}{ Loganiaceae } \\
\hline $\begin{array}{l}\text { Strychnos } \\
\text { pseudoquina A. St. Hil }\end{array}$ & Quina & $\begin{array}{l}\text { ARB } \\
\text { (cultivada) }\end{array}$ & 0,06 & Cascas & Dor no corpo, diarreia. \\
\hline
\end{tabular}


TABELA 1. Lista de plantas medicinais citadas pela Comunidade Santo Antônio, Currais, PI. Legenda: $A R B=$ arbóreo, ARS = arbusto, SUB = subarbusto, TRE = trepadeira, HEB = herbácea.

continua...

\section{Lythraceae}

\begin{tabular}{|l|l|l|l|l|l|}
\hline Punica granatum L. & Romã & $\begin{array}{l}\text { ARB } \\
\text { (cultivada) }\end{array}$ & 0,03 & $\begin{array}{l}\text { Cascas da } \\
\text { fruta }\end{array}$ & Dor de garganta. \\
\hline $\begin{array}{l}\text { Lafoensia replicata } \\
\text { Pohl. }\end{array}$ & Mangabeira & $\begin{array}{l}\text { ARB } \\
\text { (espontânea) }\end{array}$ & 1,34 & $\begin{array}{l}\text { Folhas; } \\
\text { cascas; raiz }\end{array}$ & $\begin{array}{l}\text { Ferimentos, infecção renal, infecção no aparelho } \\
\text { geniturinário feminino, diabetes, hipertensão, } \\
\text { fígado, gripe, picada de mosquito, inflamação } \\
\text { pelo corpo, úlcera de estômago, dor no } \\
\text { corpo, cicatrização, infecção em cortes, lavar } \\
\text { ferimentos, próstata, problemas intestinais. }\end{array}$ \\
\hline
\end{tabular}

Malpighiceae

\begin{tabular}{|l|l|l|l|l|l|}
\hline $\begin{array}{l}\text { Malpighia emarginata } \\
\text { DC. }\end{array}$ & Acerola & $\begin{array}{l}\text { ARS } \\
\text { (cultivada) }\end{array}$ & 0,06 & Folhas & Diabetes, gripe. \\
\hline
\end{tabular}

Malvaceae

\begin{tabular}{|c|c|c|c|c|c|}
\hline $\begin{array}{l}\text { Abelmoschus } \\
\text { esculentus (L) Moench }\end{array}$ & Quiabo & $\begin{array}{l}\text { HER } \\
\text { (cultivada) }\end{array}$ & 0,06 & $\begin{array}{l}\text { Mucilagem; } \\
\text { sementes }\end{array}$ & Pneumonia. \\
\hline Gossypium hirsutum L. & Algodão & $\begin{array}{l}\text { ARS } \\
\text { (cultivada) }\end{array}$ & 0,37 & Folhas & $\begin{array}{l}\text { Gripe, fígado, machucados, infecção urinário e } \\
\text { do ap. geniturinário feminino. }\end{array}$ \\
\hline $\begin{array}{l}\text { Luehea grandiflora } \\
\text { Mart. et Zucc }\end{array}$ & Açoita Cavalo & $\begin{array}{l}\text { ARB } \\
\text { (espontânea) }\end{array}$ & 0,06 & Cascas & Afrodisíaco, fraqueza. \\
\hline $\begin{array}{l}\text { Pseudobombax } \\
\text { marginatum (A. St-Hill, } \\
\text { Juss \& Cambess) A. } \\
\text { Robyns }\end{array}$ & Imbiruçu & $\begin{array}{l}\text { ARB } \\
\text { (espontânea) }\end{array}$ & 0,03 & Cascas & Coluna. \\
\hline $\begin{array}{l}\text { Sterculia striata A. St. } \\
\text { Hil. \& Naudin }\end{array}$ & Chichá & $\begin{array}{l}\text { ARB } \\
\text { (espontânea) }\end{array}$ & 0,06 & Folhas & Picada de cobra, dor nas pernas. \\
\hline
\end{tabular}

Moraceae

\begin{tabular}{|l|l|l|l|l|l|}
\hline Morus nigra L. & Amora & $\begin{array}{l}\text { ARB } \\
\text { (espontânea) }\end{array}$ & 0,06 & Folhas & Hipertensão. \\
\hline \multicolumn{7}{|l|}{ Musaceae } & Banana & $\begin{array}{l}\text { HER } \\
\text { (cultivada) }\end{array}$ & 0,12 & $\begin{array}{l}\text { Flores; } \\
\text { seiva }\end{array}$ & Gripe, diarreia, queimadura. \\
\hline $\begin{array}{l}\text { Musa paradisiaca L. } \\
\text { Myrtaceae }\end{array}$ & $\begin{array}{l}\text { Eucalipto } \\
\text { Eucalyptus globulus } \\
\text { Labill }\end{array}$ & $\begin{array}{l}\text { ARB } \\
\text { (cultivada) }\end{array}$ & 0,06 & Folhas & Gripe, febre. \\
\hline
\end{tabular}


TABELA 1. Lista de plantas medicinais citadas pela Comunidade Santo Antônio, Currais, PI. Legenda: ARB = arbóreo, ARS = arbusto, SUB = subarbusto, TRE = trepadeira, HEB = herbácea.

continua...

\begin{tabular}{|l|l|l|l|l|l|}
\hline $\begin{array}{l}\text { Eugenia dysenterica } \\
\text { DC }\end{array}$ & Cagaita & $\begin{array}{l}\text { ARB } \\
\text { (espontânea) }\end{array}$ & 0,03 & $\begin{array}{l}\text { Frutas; } \\
\text { folhas }\end{array}$ & Prevenção de doença. \\
\hline Psidium guajava L. & Goiaba & $\begin{array}{l}\text { ARB } \\
\text { (cultivada) }\end{array}$ & 0,40 & Folhas & Diarreia, emese, nasc. dos dentes das crianças. \\
\hline
\end{tabular}

\section{Olacaceae}

Ximenia americana $\mathrm{L}$

\begin{tabular}{|l|l|l|l|l|}
$\begin{array}{l}\text { Ameixa do } \\
\text { Cerrado }\end{array}$ & $\begin{array}{l}\text { ARB } \\
\text { (espontânea) }\end{array}$ & 0,59 & Cascas & $\begin{array}{l}\text { Infecção do ap. geniturinário feminino, intestino, } \\
\text { diabetes, fígado, infecção renal, vaginite. }\end{array}$ \\
\hline
\end{tabular}

Passifloraceae

\begin{tabular}{|l|l|l|l|l|l|}
\hline Passiflora edulis Sims & Maracujá & $\begin{array}{l}\text { TER } \\
\text { (cultivada) }\end{array}$ & 0,40 & $\begin{array}{l}\text { Folhas; } \\
\text { frutas }\end{array}$ & Hipotensão, calmante, insônia.
\end{tabular}

\section{Pedaliaceae}

\begin{tabular}{|l|l|l|l|l|l}
\hline Sesamum indicum L. & Gergelim & $\begin{array}{l}\text { HER } \\
\text { (cultivada) }\end{array}$ & 0,06 & $\begin{array}{l}\text { Sementes; } \\
\text { látex }\end{array}$ & Pneumonia. \\
\hline
\end{tabular}

\section{Poaceae}

\begin{tabular}{|l|l|l|l|l|l|}
\hline $\begin{array}{l}\text { Cymbopogon citratus } \\
\text { (DC.) Stapf. }\end{array}$ & Capim Santo & $\begin{array}{l}\text { SUB } \\
\text { (cultivada) }\end{array}$ & 0,56 & Folhas & $\begin{array}{l}\text { Hipertensão calmante, febre, gripe, cólicas } \\
\text { intestinais. }\end{array}$ \\
\hline $\begin{array}{l}\text { Saccharum officinarum } \\
\text { L. }\end{array}$ & $\begin{array}{l}\text { Cana de } \\
\text { Açúcar }\end{array}$ & $\begin{array}{l}\text { HER } \\
\text { (cultivada) }\end{array}$ & 0,15 & $\begin{array}{l}\text { Colmo; } \\
\text { folhas }\end{array}$ & Calmante hipertensão. \\
\hline
\end{tabular}

\section{Phytolacaceae}

\begin{tabular}{|c|c|c|c|c|c|}
\hline Petiveria alliacea L. & Tipi & $\begin{array}{l}\text { HER } \\
\text { (espontânea) }\end{array}$ & 0,09 & $\begin{array}{l}\text { Planta } \\
\text { inteira }\end{array}$ & Gripe, mau olhado, olho gordo. \\
\hline \multicolumn{6}{|l|}{ Rubiaceae } \\
\hline Genipa americana L. & Jenipapo & $\begin{array}{l}\text { ARB } \\
\text { (cultivada) }\end{array}$ & 0,06 & $\begin{array}{l}\text { Cascas; } \\
\text { frutas }\end{array}$ & Dor no joelho, depurativo. \\
\hline \multicolumn{6}{|l|}{ Rutaceae } \\
\hline $\begin{array}{l}\text { Citrus aurantifolia } \\
\text { (Christm.) Swingle }\end{array}$ & Lima & $\begin{array}{l}\text { ARB } \\
\text { (cultivada) }\end{array}$ & 0,09 & $\begin{array}{l}\text { Folhas; } \\
\text { cascas. }\end{array}$ & Taquicardia, calmante, hipotensão. \\
\hline Citrus limon (L.) Burm. & Limão & $\begin{array}{l}\text { ARB } \\
\text { (cultivada) }\end{array}$ & 0,18 & $\begin{array}{l}\text { Folhas; } \\
\text { cascas; } \\
\text { fruta. }\end{array}$ & Gripe, febre, fortalece os dentes das crianças. \\
\hline
\end{tabular}


TABELA 1. Lista de plantas medicinais citadas pela Comunidade Santo Antônio, Currais, PI. Legenda: $A R B=$ arbóreo, ARS = arbusto, SUB = subarbusto, TRE = trepadeira, HEB = herbácea.

continua...

\begin{tabular}{|l|l|l|l|l|l|}
\hline $\begin{array}{l}\text { Citrus sinensis (L.) } \\
\text { Osbeck. }\end{array}$ & Laranja & $\begin{array}{l}\text { ARB } \\
\text { (cultivada) }\end{array}$ & 1,09 & $\begin{array}{l}\text { Folhas; } \\
\text { cascas da } \\
\text { fruta }\end{array}$ & $\begin{array}{l}\text { Calmante, febre diarreia, dor no estomago, } \\
\text { pressão alta, cólica intestinal, dor de cabeça. }\end{array}$ \\
\hline $\begin{array}{l}\text { Ruta graveolens L. } \\
\text { Spiranthera } \\
\text { odoratissima St. Hil. }\end{array}$ & Arruda & $\begin{array}{l}\text { HER } \\
\text { (cultivada) }\end{array}$ & 0,25 & Folhas & $\begin{array}{l}\text { Cólicas menstruais e intestinais, febre, moleza } \\
\text { e dor no corpo, convulsão. }\end{array}$ \\
\hline Scrophulariaceae & $\begin{array}{l}\text { ARS } \\
\text { (espontânea) }\end{array}$ & 0,12 & Raiz & $\begin{array}{l}\text { Inflamação renal, sinusite, afina o sangue, } \\
\text { neoplasia. }\end{array}$ \\
\hline $\begin{array}{l}\text { Scoparia dulcis L. } \\
\text { Vassorinha }\end{array}$ & $\begin{array}{l}\text { HER } \\
\text { (espontânea) }\end{array}$ & 0,34 & $\begin{array}{l}\text { Planta } \\
\text { inteira; } \\
\text { folhas }\end{array}$ & $\begin{array}{l}\text { Infecção no ap. geniturinário feminino e } \\
\text { masculino e gripe, dor de dentes, puerpério, } \\
\text { diarreia. }\end{array}$ \\
\hline
\end{tabular}

\section{Smilicaceae}

\begin{tabular}{l|l|l|l|l|l}
$\begin{array}{l}\text { Smilax brasiliensis } \\
\text { Spreng. }\end{array}$ & Japecanga & $\begin{array}{l}\text { HER } \\
\text { (espontânea) }\end{array}$ & 0,03 & Raiz & Neoplasia.
\end{tabular}

\section{Solanaceae}

\begin{tabular}{|l|l|l|l|l|l}
\hline Solanum physalis L. & Bobola & $\begin{array}{l}\text { HER } \\
\text { (espontânea) }\end{array}$ & 0,06 & Raiz & Pneumonia, gripe.
\end{tabular}

Turneraceae

\begin{tabular}{|l|l|l|l|l|l}
\hline Turnera guanensis L. & $\begin{array}{l}\text { Arranca } \\
\text { estrepe }\end{array}$ & $\begin{array}{l}\text { HER } \\
\text { (espontânea) }\end{array}$ & 0,03 & Folhas & Retirada de espinhos e ferpas de madeira. \\
\hline
\end{tabular}

\section{Violaceae}

\begin{tabular}{|l|l|l|l|l|l}
\hline $\begin{array}{l}\text { Hybanthus calceolaria } \\
\text { (L.) Oken }\end{array}$ & Papaconha & $\begin{array}{l}\text { HER } \\
\text { (espontânea) }\end{array}$ & 0,06 & Raiz & Sarampo, gripe. \\
\hline
\end{tabular}

\begin{tabular}{|l|l|l|l|l|l|} 
Verbenaceae & Erva Cidreira & $\begin{array}{l}\text { HER } \\
\text { (cultivada) }\end{array}$ & 1,43 & Folhas & $\begin{array}{l}\text { Calmante, cólicas intestinais, febre, hipertensão, } \\
\text { diarreia, regulador intestinal, gripe, conjuntivite, } \\
\text { náuseas, cólicas do recém-nascido. }\end{array}$ \\
\hline Lippia gracillis Schauer & $\begin{array}{l}\text { Alecrim de } \\
\text { Chapada }\end{array}$ & $\begin{array}{l}\text { HER } \\
\text { (espontânea) }\end{array}$ & 1,12 & $\begin{array}{l}\text { Folhas; } \\
\text { galhos }\end{array}$ & $\begin{array}{l}\text { Gripe forte, febre, resfriado, sinusite, caspa, } \\
\text { obstrução nasal, prurido, dor de cabeça, } \\
\text { problema na pele, tosse, labirintite. }\end{array}$ \\
\hline
\end{tabular}

\section{Winteraceae}

\begin{tabular}{|l|l|l|l|l|l|}
\hline $\begin{array}{l}\text { Drimys winteri J.R. } \\
\text { Forst. \& G. Forst. }\end{array}$ & Pau Pratudo & $\begin{array}{l}\text { ARB } \\
\text { (espontânea) }\end{array}$ & 0,18 & Cascas & Dor no corpo e estômago, obstrução nasal. \\
\hline
\end{tabular}


TABELA 1. Lista de plantas medicinais citadas pela Comunidade Santo Antônio, Currais, PI. Legenda: $A R B=$ arbóreo, $A R S$ = arbusto, SUB = subarbusto, TRE = trepadeira, HEB = herbácea.

continua..

\begin{tabular}{|l|l|l|l|l|l|l|}
\hline \multicolumn{6}{|l|}{ Urticaceae } \\
\begin{tabular}{|l|l|l|l|l|l|} 
Cecropia glaziovii \\
Snethlage
\end{tabular} & Embaúba & $\begin{array}{l}\text { ARB } \\
\text { (espontânea) }\end{array}$ & 0,06 & Raiz & Depurativo, diurético. \\
\hline Zingiberiaceae & Gengibre & $\begin{array}{l}\text { HER } \\
\text { (cultivada) }\end{array}$ & 0,12 & Raiz & Tosse, gripe, infecção da garganta. \\
\hline $\begin{array}{l}\text { Zingiber officinalis } \\
\text { Roscoe }\end{array}$ & Açafrão & $\begin{array}{l}\text { HER } \\
\text { (cultivada) }\end{array}$ & 0,18 & Raiz & Sarampo, catapora, gripe, infecção urinária. \\
\hline Curcuma longa L. & $\begin{array}{l}\text { Imburana } \\
\text { Rasteira }\end{array}$ & $\begin{array}{l}\text { HEB } \\
\text { (sem dados) }\end{array}$ & 0,09 & Raiz & Dor no corpo, câncer de próstata. \\
\hline & Bananinha & $\begin{array}{l}\text { HERB } \\
\text { (espontânea) }\end{array}$ & 0,03 & Folhas & Gripe. \\
\hline & Jarrinha & $\begin{array}{l}\text { HER } \\
\text { (cultivada) }\end{array}$ & 0,03 & Raiz & Sarampo. \\
\hline
\end{tabular}

(Tabela 1).

As categorias de indicações terapêuticas que obtiveram mais citações foram às relacionadas ao sistema digestivo (25\%) e o respiratório com $21 \%$ (Figura 1). Esses resultados podem relacionar-se à falta de saneamento básico na região, uma vez que a comunidade não apresenta tal infra-estrutura tornando-se comum, por exemplo, sintomas como a diarréia, dores abdominais, verminoses e infecções intestinais. Para o presente trabalho foi visto que os recursos vegetais terapêuticos não são utilizados pelos entrevistados como fonte de renda ou troca, pois coletam apenas a quantidade necessária para preparar a medicação caseira que será usada durante o tratamento da doença.

O valor de uso (VU) calculado para cada espécie variou de 0,03 a 1,59 (Tabela 1), contudo nove espécies destacaram-se por apresentarem o VU maior ou igual a 1: Amburana cearensis (Allemao) A. C. Sm (imburana) (1,59), Lippia alba (Mill) N. E. Brown (erva cidreira) $(1,43)$, Operculina sp. (batata de purga) $(1,40)$, Lafoensia replicata Pohl. (mangabeira) $(1,34)$, Lippia gracillis H. B. K. (alecrim da chapada) $(1,12)$, Citrus sinensis (L.) Osbeck (laranja) $(1,09)$, Chenopodium ambrosioides L. (mastruz) $(1,0)$. De acordo com os informantes, a grande quantidade de indicações e, conseqüentemente alto valor de uso, se deve pela frequência da coleta destas plantas, devido a grande quantidade de doenças respiratórias e do sistema digestivo. A fácil localização de algumas dessas espécies, por exemplo, o mastruz ( $C$. ambrosioides L.), a erva cidreira (L. alba (Mill) N. E. Brown) e a laranja (C. sinensis (L.) Osbeck), que são cultivadas em espaços próprios ou encontradas em quintais vizinhos, também auxilia para a coleta visando os processos de cura.

\section{Dinâmica do conhecimento na Comunidade Santo Antonio, Currais, Piauí \\ Verificou-se que não houve distinções} significativas referentes à quantidade de citações do uso das plantas medicinais utilizadas na comunidade entre os gêneros $(p>0,05 ; F=2,31)$ e grau de escolaridade ( $p>0,05 ; H=0,40)$, reforçando assim, a homogeneidade do saber informal no emprego das plantas terapêuticas pelos informantes. Tal fato foi confirmado ao se avaliar a diversidade de plantas citadas, onde não se obteve diferenças significativas $(p>0,05)$ entre homens e mulheres, apresentando respectivamente valores de 3,96 bits e 3,94 bits

No entanto, a correlação entre as variáveis: idade, gênero, escolaridade e renda revelaram que apenas as duas primeiras foram significativamente correlacionadas com o número de plantas citadas pelos informantes da comunidade ( $r s=0,713$,

Rev. Bras. PI. Med., Campinas, v.16, n.2, supl. I, p.406-425, 2014. 


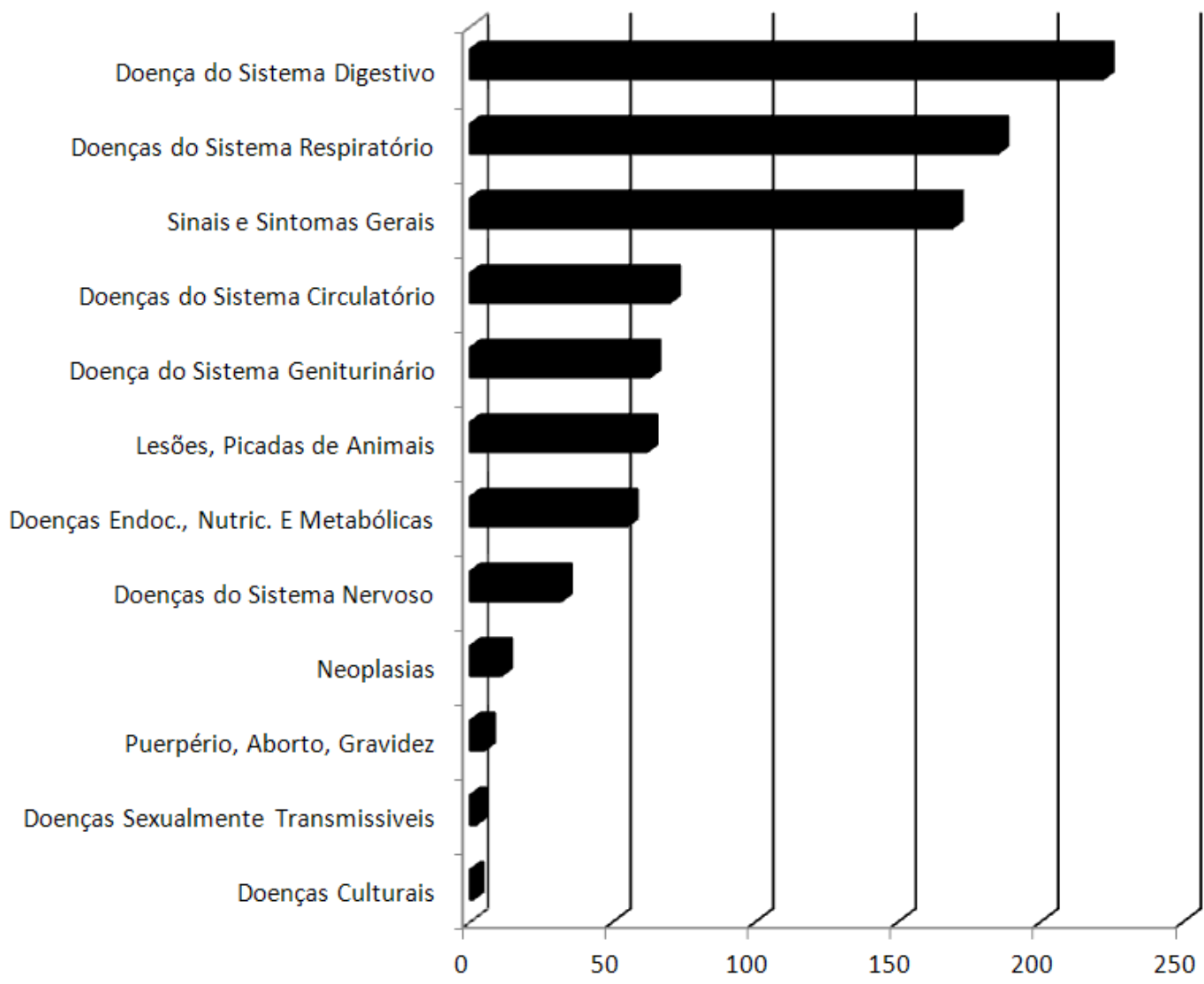

FIGURA 1. Categorias das indicações terapêuticas do uso de plantas medicinais, na Comunidade Santo Antonio, Currais, Piauí.

$p<0,0001$, para idade; $r s=-0,451, p<0,0141$, para o gênero). Enquanto que para a análise de regressão linear múltipla, o coeficiente de determinação $\mathrm{R}^{2}$ encontrado indicou que $45,2 \%$ da variabilidade total da quantidade de plantas citadas podem ser explicadas apenas pela idade $(T=3,664, \mathrm{P}<0,001)$, constatando-se que pessoas de idade mais avançada citaram um maior número de plantas quando comparadas as pessoas mais jovens.
Ao estimar a riqueza de espécies mencionadas localmente observou-se que há tendência para estabilidade (Figura 2). Observaramse diferentes performances dos índices empregados. O valor máximo observado (Nobs) foi de 121 espécies, sendo que os três estimadores utilizados revelaram valores de estimativa diferentes, sendo de Nest=180,11 (Chao 2); Nest=170,41 (Jacknife 1) e Nest=142,71(Bootstrap).

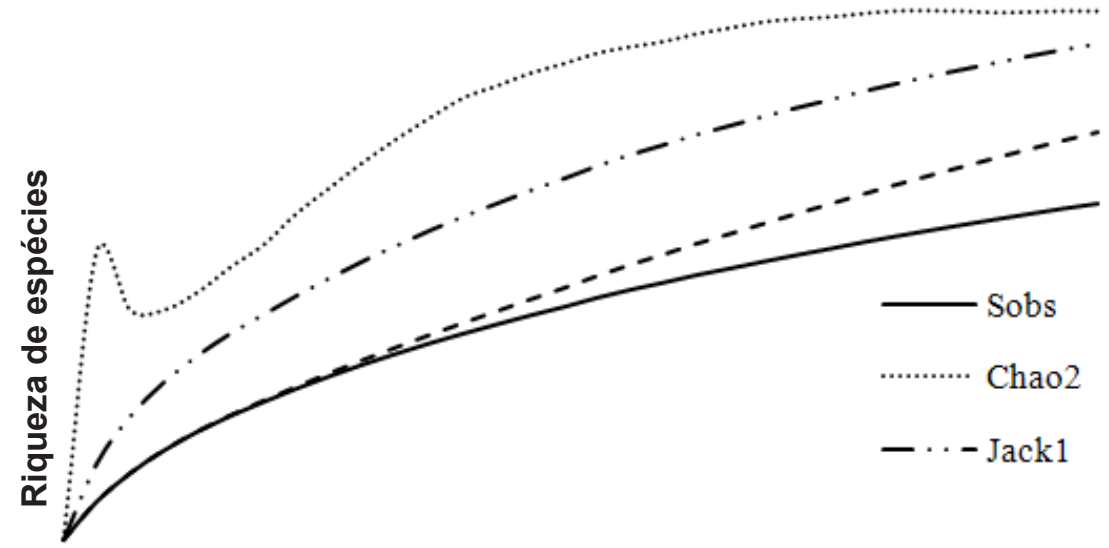

Informantes

FIGURA 2. Curva de rarefação para as plantas citadas pela Comunidade de Santo Antonio, Currais, Sul do Piauí. 


\section{DISCUSSÃO}

\section{Diversidade de plantas medicinais}

A riqueza de plantas medicinais citadas para o presente trabalho foi considerada elevada se comparado a algumas pesquisas. Por exemplo, Santos et al. (2007) encontraram 70 espécies medicinais e forrageiras numa vegetação típica de cerrado em Monsenhor Gil, Piauí. Abreu (2000) trabalhou com quilombolas Mimbó em Amarante, Piauí, registrou 73 espécies, sendo $48 \%$ usadas na terapia local. Já alguns resultados encontrados para o estado do Piauí foram semelhantes a este quanto a riqueza de espécies úteis e também registraram mais de 100 espécies. Numa comunidade do semiárido pernambucano onde foi encontrado um total de 136 espécies medicinais (Silva et al., 2010). Oliveira et al. (2010) em Oeiras, Piauí, encontrou 167 espécies medicinais. Já Souza (2010) encontrou 211 espécies úteis e destacou a categoria medicinal em seu trabalho com comunidades pesqueiras da área de Proteção Ambiental do Delta do Parnaíba, Piaui. Observou-se ainda que a família botânica com mais destaque, apresentando maior número de indivíduos foi a Fabaceae. No Brasil é representada com 175 gêneros e 1500 espécies podendo ser encontrada em qualquer bioma (Lorenzi, 2008). Essa família está bem representada por elementos úteis em alguns estudos etnobotânicos (Franco et al., 2007; Santos et al., 2007; Monteiro et al., 2011). Em estudo com duas comunidades pernambucanas, Silva \& Andrade (2005) inventariaram 334 espécies úteis das quais 169 são medicinais. A alta diversidade de espécies conhecidas pode ser reflexo da riqueza cultural da região. O nordeste brasileiro é composto por diferentes comunidades étnicas, como os ameríndios e quilombolas (descendentes de escravos africanos), cujas culturas distintas contribuíram fortemente para a diversidade local de plantas medicinais usadas, de acordo com Albuquerque et al. (2007b). Esse aspecto é explicado pela forte tradição nos processos de cura a partir de produtos vegetais por populações sertanejas (Diegues \& Arruda, 2002), pois detém um profundo conhecimento da natureza e seus ciclos, reproduzindo seu estilo de vida historicamente adaptando-se aos nichos específicos locais (Diegues \& Arruda, 2002).

A maioria das plantas citadas no presente trabalho foi considerada espontânea tal como alguns trabalhos já realizados no Piauí (Abreu, 2000; Vieira, 2008; Oliveira et al., 2010). Das espécies terapêuticas com maior número de citações, onze são consideradas nativas na região da Comunidade Rural Santo Antonio: imburana [Amburana cearensis (Allemao) A. C. Sm], batata de purga (Operculina sp.), mangabeira (Lafoensia replicata Pohl.), alecrim de chapada (Lippia gracillis H.B.K.), aroeira (Myracroduon urundeuva Allemão), catinga de porco (Terminalia brasiliensis Camb), pau de rato (Caesalpinia bracteosa Tul.), jatobá (Hymenaea stigonocarpa var. pubescens Benth), pau d'óleo (Copaifera langsdorffii Desf.) e inharé (Brosimum gaudichaudii Trecul.). Dessas espécies, destaca-se a Myracroduon urundeuva Allemão (aroeira) que é amplamente conhecida e utilizada em diversas categorias de uso, como madeireiro, combustível e principalmente como medicinal. Grandes quantidades de cascas do caule desta planta e muitas outras nativas são comercializadas em mercados e feiras públicas do nordeste do Brasil (ver Monteiro et al., 2012), e ainda há lacunas sobre o conhecimento do comércio em mercados e feiras livres sobre essas espécies nativas para o nordeste brasileiro. Ademais, as cascas do caule dessas espécies são apontadas como curativas devido aos altos teores de compostos fenólicos do metabolismo secundário, especificamente os taninos. Esses compostos fenólicos (taninos) possuem a habilidade de formar complexos insolúveis em água com proteínas e devido a essa propriedade, apresentam uma série de atividades biológicas, entre elas, a adstringência, a ação cicatrizante e antiinflamatória (Mello \& Santos, 2001; Monteiro et al., 2005). De acordo com os resultados da 1a Reunião Técnica intitulada "Estratégias para Conservação e Manejo de Recursos Genéticos de Plantas Medicinais e Aromáticas" a aroeira do sertão, também a imburana e o angico foram apontados como espécies de alta prioridade para conservação in situ (Vieira et al., 2002). Em documento mais recente, M. urundeuva Allemão consta juntamente com Amburana cearensis (Allemao) A. C. Sm numa lista de espécies, publicada em 23 de setembro de 2008, como vulnerável, isto é, podem tornar-se ameaçadas no futuro se não forem tomadas medidas mitigadoras para conter a exploração (MMA, 2008).

Das plantas citadas pelos informantes, $56 \%$ apresentaram hábitos arbóreos e $29 \%$ herbáceos. Resultados similares foram encontrados para o Piauí e até outros biomas. Santos et al. (2007) verificaram que o hábito arbustivo representou $47 \%$ e o arbóreo cerca de $39 \%$ das plantas medicinais citadas no município de Monsenhor Gil, Piauí. Silva (2010), em Campo Maior, também no Piauí, obteve para o hábito arbóreo $36,2 \%$ e herbáceo $22,7 \%$, no entanto Roque et al. (2009) obtiveram como resultados $37 \%$ das plantas com hábito herbáceo e $34 \%$ arbóreo em estudo realizado em Caicó, Rio Grande do Norte. Dessa forma, a variabilidade dos resultados sobre os hábitos das plantas utilizadas como medicinal nas comunidades tradicionais é influenciada pela cultura e disponibilidade vegetal local. Por exemplo, Albuquerque (2006) sugeriu a

Rev. Bras. PI. Med., Campinas, v.16, n.2, supl. I, p.406-425, 2014. 
hipótese da sazonalidade para explicar a preferência por determinados recursos perenes. Esse autor pontuou que no semiárido brasileiro as pessoas tendem a preferir plantas nativas e lenhosas em detrimento das herbáceas não perenes.

Nesse trabalho a parte da planta mais empregada pelos entrevistados foram as folhas $(28 \%)$, seguidas da casca/entrecasca (18\%), e raízes $(11 \%)$, utilizadas como chás (infusão ou decocção), garrafadas, xaropes, pó, banhos e emplastos. Em estudo semelhante Oliveira et al. (2010) observaram que as folhas representavam $31,5 \%$ das indicações para preparar os tratamentos pelos informantes de Oeiras, Piauí e Vieira (2008) no Município de São Miguel, também no Piauí, destacou o uso das folhas com $36,98 \%$. Contudo, durante a estação seca, período em que há pouca disponibilidade de folhas, a parte mais utilizada são as cascas/entrecascas das espécies arbóreas que tenham os mesmos efeitos sobre a sintomatologia de algumas doenças.

Quanto às categorias de indicações terapêuticas houve resultados concordantes com o presente trabalho. Giraldi \& Hanazaki (2010) também encontraram um maior número de indicações para problemas do sistema digestivo. Resultados semelhantes também foram registrados por Franco \& Barros (2006), no Quilombo Olho D'água, em Esperantina, Piauí, cujos maiores números de indicações foram para doenças do sistema respiratório com $26,7 \%$ de indicações (entre elas: gripe, asma, sinusite, inflamação da garganta e tosse) e doenças do sistema digestivo, 19,2\% (diarréia, helmintíases, infecções intestinais, hepáticas e gástricas). Algumas doenças apontadas pelos informantes da presente pesquisa foram categorizadas como 'doenças culturais'. Duas informantes afirmaram apenas manter na residência o tipi (Petiveria tetranda Gomez) para afastar o 'mau olhado' e 'olho gordo'. Giraldi \& Hanazaki (2010) num estudo realizado no Sertão do Ribeirão, Florianópolis, pontuaram que tais doenças são tratadas localmente por práticas culturais chamadas de benzeduras, e as benzedeiras, pessoas geralmente mais velhas, são especialistas locais e muito procuradas para a cura desses transtornos.

\section{Dinâmica do conhecimento e valor de uso}

Tal qual a presente pesquisa, alguns autores perceberam que o grau de escolaridade $e$ a renda mensal dos informantes não influenciaram na quantidade de citação de plantas. Giraldi \& Hanazaki (2010) no Sertão do Ribeirão, SC, também constataram que o gênero não influenciou na pesquisa, porém esse resultado pode ser explicado devido o baixo número de entrevistas realizadas, destacaram as autoras. Em pesquisa realizada com 101 informantes acerca de duas espécies medicinais numa comunidade do interior de Pernambuco, Monteiro et al. (2010) também não perceberam distinções significativas quanto ao gênero. Ao contrário, encontraram-se aqui distinções significativas na quantidade de conhecimento entre jovens e pessoas mais velhas. Resultados similares foram encontrados na literatura (Almeida et al., 2010; Monteiro et al., 2010). Esse tipo de resultado é largamente esperado, devido a maior experimentação e vivências dos mais velhos. A 'erosão do conhecimento' que também poderia explicar as diferenças entre classes de idade já foi bem pontuada por vários autores, como também a "aculturação", mas ambos os processos devem ser discutidos com parcimônia, pois é perfeitamente plausível que jovens conheçam menos que os mais velhos, dessa forma não pode-se afirmar aqui que tal resultado sinaliza perda da cultura local (Almeida et al., 2010; Silva et al., 2011). Ao considerar o menor conhecimento dos mais jovens, refletido aqui em quantidade de indicações de uso, alguns autores pontuaram em seus trabalhos que a influência de outras culturas, a modernidade e a até a existência de Postos de Saúde (acesso facilitado aos medicamentos industrializados) tem contribuído para diminuir o interesse e a transmissão dos conhecimentos empíricos sobre o uso das plantas pelos jovens (Vandebroek et al., 2004; Guarim Neto \& Carniello, 2007).

Pesquisas etnobotânicas que utilizam técnicas e ferramentas para quantificar o conhecimento tradicional têm aumentado visivelmente (Silva et al., 2010; Araujo et al., 2012). O indicador usado aqui para avaliar o conhecimento botânico local, o valor de uso, foi selecionado pela sua praticidade e relativa rapidez na aplicação, enquadrando-se no conceito das técnicas denominadas de "consenso dos informantes" (Rossato et al., 1999; Monteiro et al., 2006; Silva et al., 2010; Araujo et al., 2012). Propicia ainda a vantagem de propor comparações entre as respostas dos informantes sobre um determinado domínio cultural pesquisado, além de permitir inferências estatísticas. Dentre as espécies espontâneas que apresentaram um alto $\mathrm{VU}$ neste trabalho (maior ou igual a 1), estão Amburana cearensis (Allemao) A. C. Sm., muito usada para o tratamento de tosses e gripes e Myracrodruon urundeuva Allemao, onde o decocto de suas cascas é amplamente utilizado para inflamações, pancadas ou gastrite. Em várias localidades, incluindo a caatinga, muitas árvores são usadas como medicinais, atribuindo-se as cascas seu poder curativo (Zschocke et al., 2000; Monteiro et al., 2006). Essas plantas estão submetidas à coleta sistemática de cascas, podendo formar um anelamento, prática destrutiva de colheita e fatalmente atinge o vegetal, além do mais, essas

Rev. Bras. PI. Med., Campinas, v.16, n.2, supl. I, p.406-425, 2014. 
espécies arbóreas mais populares tem tanto crescimento como reprodução lentos (Zschocke et al., 2000), o mesmo ocorrendo com muitas das plantas medicinais da caatinga.

\section{CONSIDERAÇÕES FINAIS}

De acordo com as informações obtidas neste trabalho, diferentes aplicações de uso da vegetação medicinal local foram apontadas em consonância com a riqueza encontrada aqui, confirmando a importância do vegetal na comunidade estudada. Soma-se ao fato a riqueza da flora piauiense, marcada por apresentar áreas de transição entre caatinga e cerrado na região sul, oferecendo uma oportunidade ímpar para o desenvolvimento de pesquisas abrangendo o escopo da biodiversidade vegetal e do conhecimento tradicional associado (Farias, 2003). Pesquisas para essa região ainda são escassas e fazem-se necessários mais estudos com distintas abordagens, para somar aos resultados aqui apresentados, que envolvam a influência de fatores culturais: idade, gênero e ocupação das pessoas na distribuição do conhecimento e uso de plantas úteis, a fatores ecológicos: identificação e contagens de indivíduos, acesso aos sítios de coleta e quantidade coletada, por exemplo. Tais questões podem favorecer a implementação de propostas conservacionistas para a região, pois, pesquisas etnodirigidas que identifiquem recursos muito demandados localmente, por exemplo a aroeira ( $M$. urundeuva Allemão), podem auxiliar gestores a solucionar os problemas de interesse, especialmente na urgente tomada de decisões políticas sobre o manejo desses recursos.

\section{REFERÊNCIA}

ABREU, J.R. Diversidade de recursos vegetais do cerrado utilizados pelos quilombolas Mimbó (Amarante, Piauí, Brasil). Dissertação (Mestrado) Universidade Federal de Pernambuco, Recife, 2000.

ALBUQUERQUE, U.P. Introdução a etnobotânica. Editora Interciência. $2^{\circ}$ ed. 93p. 2005.

ALBUQUERQUE, U.P., ANDRADE, L.H.C.,. Etnobotanica del genero Ocimum L. (Lamiaceae) en las comunidades afrobrasilenas. An. Jard. Bot. Madrid, v. 56, n. 1, p. 107-118. 1998.

ALBUQUERQUE, U.P.; ANDRADE, L.H.C. Conhecimento botânico tradicional e conservação em uma área de caatinga no Estado de Pernambuco, Nordeste do Brasil. Acta Botanica Brasilica, v. 16, n. 3, p. 273-285. 2002 ALBUQUERQUE, U.P., MEDEIROS, P.M., ALMEIDA, A.L.S., MONTEIRO, J.M., LINS, E.M.F., MELO, J.G., SANTOS, J.P. Medicinal plants of the caatinga (semiarid) vegetation of NE Brazil: a quantitative approach. Journal of Ethnopharmacology v. 114, p. 325-354. 2007a.
ALBUQUERQUE, U.P., MONTEIRO, J.M., RAMOS, M.A., AMORIM, E.L.C. Medicinal and magic plants from a public market in northeastern Brazil. Journal of Ethnopharmacology v. 110, p. 76-91. 2007b.

ALBUQUERQUE, U.P.; LUCENA, R.F.P.; ALENCAR, N.L. Métodos e técnicas para coleta de dados etnobotânicos. In: ALBUQUERQUE, U.P.; LUCENA, R.F.P; CUNHA, L.V.F.C. Métodos e técnicas na pesquisa etnobotânica, Comunigraf, Recife/PE, 2008.

ALBUQUERQUE, U.P.; ARAÚJO, T.A.S.; RAMOS, M.A.; NASCIMENTO, V.T.; LUCENA, R.F.P.; MONTEIRO, J.M.; ALENCAR, N.L.; ARAÚJO, E.L. How ethnobotany can aid biodiversity conservation: reflections on investigations in the semi-arid region of NE Brazil. Biodiversity and Conservation, v. 18, p. 127-150. 2009.

ALMEIDA, C.F.C.B.R.; RAMOS, M.A.; AMORIM, E.L.C.; ALBUQUERQUE, U.P. A comparison of knowledge about medicinal plants for three rural communities in the semi-arid region of northeast of Brazil. Journal of Ethnopharmacology, v. 127, p. 674-684, 2010.

AMORIM, A. Etnobiologia da Comunidade de Pescadores Artesanais Urbanos do Bairro Poti Velho, Teresina/PI, Brasil, In: LOPES, W.G.R. et al. (Orgs.). Cerrado piauiense: uma visão multidisciplinar, EDUFPI, Série Desenvolvimento e Meio Ambiente, Teresina/PI, 2010.

ARAÚJO, T.A.S.; ALENCAR, N.L.; AMORIM, E.L.C.; ALBUQUERQUE, U.P. A new approach to study medicinal plants with tannins and flavonoids contents from the local knowledge. Journal of Ethnopharmacology, v. 120, p. 72-80, 2008.

ARAÚJO, T.A.S.; ALMEIDA, A.L.S.; MELO, J.G.; MEDEIROS, M.F.T.; RAMOS, M.A.; SILVA, R.; ALMEIDA, C.F.C.B.R.; ALBUQUERQUE, U.P. A new technique for testing distribution of knowledge and to estimate sampling sufficiency in ethnobiology studies. Journal of Ethnobiology and Ethnomedicine, v. 8, p. 1-11, 2012.

AYRES, M, AYRES, M.J.; AYRES, D.L.; SANTOS, S.A. Bioestat 5.0: aplicações estatísticas nas áreas das ciências biológicas e médicas. Sociedade Civil Mamirauá, CNPq, Brasília/DF, 2007.

BREMER, K. An Update of the Angiosperm Phylogeny Group classification for the orders and familles of flowering plants: APG III. Botanical Journal of the Linnean Society, 2009.

CASTRO, A.A.J.F.;BARROS, J.S.; COSTA, J.M. da; SANTOS, M.P.D.; PIRES, M.F.O.; MENDES, M.R.A.; CASTRO, N.M.C.F.; FARIAS, R.R.S.; SOUSA, S.R. Cerrados marginais do nordeste e ecótonos associados: Sítio 10 do PELD (período 2001/2011). Teresina: EDUFPI/Gráfica do Povo, 2010.

COLWELL, R.K. EstimateS: Statistical estimation of species of species richness and shared species from samples. Version 8.2. Disponível em: http://viceroy. eeb.uconn.edu/Colwell/ (acesso em: 08/08/2012).

DIEGUES, A.C.; ARRUDA, R.S.V. Saberes tradicionais e biodiversidade no Brasil. Brasília: Ministério do Meio Ambiente. São Paulo: USP, Biodiversidade, v. 4. 2001.

Emperaire, L. Végetation et gestion des resources naturelles dans la caatinga du sudest du Piauí

Rev. Bras. PI. Med., Campinas, v.16, n.2, supl. I, p.406-425, 2014. 
(Brésil). Doctorat d'Etat ès Sciences Naturelles. Université Pierre et Marie Curie, Paris. 1989.

FARIAS, R.R.S. Florística e fitossociologia em trechos de vegetação do Complexo de Campo Maior/ Piauí. Dissertação (Mestrado) - Universidade Federal de Pernambuco, Recife/PE, 2003.

FRANCO, E.A.P.A.; BARROS, R.F.M.; ARAUJO, J.L.L. Uso e diversidade de plantas do cerrado utilizadas pelos quilombolas de Olho D'água dos Pires, Esperantina, Piauí. In: LOPES, W.G.R. et al. (Orgs.). Cerrado piauiense: uma visão multidisciplinar. EDUFPI, Série Desenvolvimento e Meio Ambiente, Teresina/PI, 2007.

GIRALDI, M.; HANAZAKI, N. Uso e conhecimento tradicional de plantas medicinais no Sertão do Ribeirão. Acta Botânica Basílica, v. 24, n. 2. 2010.

GIULIETTI, A.M.; HARLEY, R.M.; QUEIROZ, L.P.; BARBOSA, M.R.V.; BEZERRA-NETA, A.L.; FIGUEIREDO, M.A. 2002. Espécies endêmicas da caatinga. p. 103-119. In: SAMPAIO, E.V.S.B.; GIULIETTI, A.M.; VIRGINIO, J.; GAMARRA-ROJAS, C.F.L. (editores). Vegetação e flora da caatinga. APNE - CNIP. 176p.

GOTELLI, N.J.; ENTSMINGER, G.L. EcoSim: null models software for ecology. Version 7. Acquired Intelligence Inc. \& Kesey-Bear. Jericho, VT 05456. 2009. Disponível em: http://www.garyentsminger.com/ecosim/ index.htm. (Acesso em fevereiro de 2010).

GUARIMNETO, G.; CARNIELLO, M.A. Etnoconhecimento e saber local: um olhar sobre populações humanas e os recursos vegetais. In: ALBUQUERQUE, U.P.; ALVES, A.G.C.; ARAÚJO, T.A.S. Povos e paisagens: Etnobiologia, etnoecologia e biodiversidade no Brasil.,NUPEEA/UFRPE, Recife/PE, 2007.

INSTITUTO BRASILEIRO DE GEOGRAFIA E ESTATISTICA (IBGE). Cidades. 2008. Disponível em: $<$ http://www.ibge.gov.br/cidadesat/default.php>. Acesso em: 15/05/ 2011.

LORENZI, H., Árvores Brasileiras: manual de identificação e cultivo de plantas arbóreas nativas do Brasil, vol. 1, $5^{\mathrm{a}}$ edição, Plantarum, 2008.

MELLO, J.P.C.; SANTOS, S.C. Taninos. In: SIMÕES, C.M.O.; SCHENCKEL, E.P. (Orgs.). Farmacognosia (da planta ao medicamento). Ed. UFSC $5^{\circ}$ ed. p.615657. 2001.

MINISTÉRIO DO MEIO AMBIENTE. Instrução Normativa №6. Disponível em: www.mma.gov.br/. (Acessado em: novembro de 2008).

MOBOT - Missouri Botanical Garden, Tropicos (on line). Disponivel em:<< http://www.mobot.org >> (Acessado em 26/04/2011)

MONTEIRO, J.M.; ARAUJO, E.L.; AMORIM, E.L.C.; ALBUQUERQUE, U.P. Taninos: uma abordagem da química a ecologia. Química Nova, v. 28, n. 5, p. 892896. 2005.

MONTEIRO, J.M.; ALBUQUERQUE, U.P.; LINS NETO, E.M.F.; ARAÚJO, E.L.; AMORIM, E.L.C. Use patterns and knowledge of medicinal species among two rural communities in Brazil's semi-arid northeastern region. Journal of Ethnopharmacology, v. 105, p. 173-186. 2006.

MONTEIRO, J.M.; RAMOS, M.A.; ARAÚJO, E.L.; AMORIM, E.L.C.; ALBUQUERQUE, U. P. Dynamics of medicinal plants knowledge and commerce in an urban ecosystem (Pernambuco, Northeast Brazil). Environmental Monitoring and Assessment, v. 178, p. 179-202, 2011.

MONTEIRO, J.M. ; ARAÚJO, E.L.; AMORIM, E.L.C.; ALBUQUERQUE, U.P. Valuation of the Aroeira (Myracrodruon urundeuva Allemão): perspectives on conservation. Acta Botanica Brasílica, v. 26, p. 125132, 2012.

OLIVEIRA, F.C.; ALBUQUERQUE, U.P.; FONSECAKRUEL, V.S.; HANAZAKI, N. Avanços nas pesquisas etnobotânicas no Brasil. Acta Botanica Brasilica, v. 23, p. 590-605, 2009.

OLIVEIRA, F.C.S BARROS R.F.M., MOITA NETO J.M. Plantas utilizadas em comunidades rurais de Oeiras - semiárido piauiense. Revista Brasileira de Plantas Medicinais, v. 12, n. 3, 2010.

RODAL, M.J.N.; SAMPAIO, E.V.S.B. A vegetação do bioma caatinga. In: E.V.S.B. Sampaio; A.M. Giulietti; J. Virgínio\& C.F.L. Gamarra-Rojas (orgs.). Vegetação e Flora da Caatinga, APNE/ CNIP, Recife/PE, 2002.

ROQUE, A.A.; ROCHA, R.M.; LOIOLA, M.I.B. Uso e diversidade de plantas medicinais da Caatinga na comunidade rural de Laginhas, município de Caicó, Rio Grande do Norte (nordeste do Brasil), Revista Brasileira de Plantas Medicinais, v.12, n.1, 2010.

ROSSATO, S.C.; LEITAO FILHO, H.; BEGOSSI, A. Ethnobotany of caiçaras of the Atlantic Forest Coast (Brazil). Economic Botany, v. 53. P. 387-395.

SANTOS, L.G.P.; BARROS, R.F.M.; ARAÚJO, J.L.L. Diversidade de plantas medicinais e forrageiras do cerrado de Monsenhor Gil, Piauí. In: LOPES, W.G.R. et al. (Orgs.). Cerrado piauiense: uma visão multidisciplinar. Teresina: EDUFPI, (Série Desenvolvimento e Meio Ambiente). 2007.

SILVA, A.J.R; ANDRADE, L. C.H. Etnobotânica nordestina: estudo comparativo da relação entre comunidades e vegetação na Zona do Litoral - Mata do Estado de Pernambuco, Brasil. Acta Botanica Brasilica, v. 19, n. 1, p. 45-60. 2005.

SILVA, M.P. Etnobotânica de Comunidades Rurais da Serra de Campo Maior - Piauí, Brasil, In: LOPES, W.G.R. et al. (Orgs.). Cerrado piauiense: uma visão multidisciplinar, EDUFPI: Série Desenvolvimento e Meio Ambiente, Teresina/PI, 2010.

SILVA, V. A.; NASCIMENTO, V. T.; SOLDATI, G. T.; MEDEIROS, M. F. T.; ALBUQUERQUE, U. P. Técnicas para análise de dados etnobiológicos. In: ALBUQUERQUE, U.P.; LUCENA, R.F.P.L.; CUNHA, L.V.C. (Org.). Métodos e Técnicas na Pesquisa Etnobiológica e Etnoecológica. Métodos e Técnicas na Pesquisa Etnobiológica e Etnoecológica. Recife: Nupeea, p. 207-222. 2010

SILVA, F. S.; RAMOS, M. A.; HANAZAKI, N.; ALBUQUERQUE, U. P. Dynamics of traditional knowledge of medicinal plants in a rural community in the Brazilian semi-arid region. Revista Brasileira de Farmacognosia, v. 21, p. 382-391, 2011.

SOUSA, R.S. Etnobotânica e Etnozoologia de Comunidades Pesqueiras da Área de Proteção Ambiental (Apa) do Delta do Parnaíba, Nordeste do Brasil. Dissertação (Mestrado) - Programa de Pós-Graduação em Desenvolvimento e Meio Ambiente

Rev. Bras. PI. Med., Campinas, v.16, n.2, supl. I, p.406-425, 2014. 
da Universidade Federal do Piauí (PRODEMA/UFPI/ TROPEN), 2010.

SOUSA, R.S.; HANAZAKI, N.; LOPES, J.B.; BARROS, R.F.M. Are gender and age important in understanding the distribution of local botanical knowledge in fishing communities of the parnaíba delta environmental protection area? Ethnobotany Research \& Applications, v. 10, p. 551-559, 2012.

TITIEV, M. Introdução à antropologia cultural. Fundação Calouste Gulbenkian. 8 ed. 2000.

VANDEBROEK, I.; CALEWAERT, J.; DE JONCKHEERE, S.; SANCA, S.; SEMO, L.; VAN DAMME, P.; VAN PUYVELDE, L.; DE KIMPE, N. Use of medicinal plants and pharmaceuticals by indigenous communities in the Bolivian Andes and Amazon. Bulletin of ter World Health Organization, v. 82, n. 4, p. 243-250. 2004.

VIEIRA, R. F.; SILVA, S. R.; ALVES, R. B. N.; SILVA, D. B.; WETZEL, M. M. V. S.; DIAS, T. A. B.; UDRY, M. C.; MARTINS, R. C. Estratégias para Conservação e Manejo de Recursos Genéticos de Plantas Medicinais e Aromáticas: Resultados da 1aReunião Técnica. Embrapa/lbama/CNPq. 184p. 2002.

VIEIRA, F. J. Uso e diversidade dos recursos vegetais utilizados pela Comunidade Quilombola dos Macacos, São Miguel do Tapuio, Piauí, Brasil. Dissertação (Mestrado em Desenvolvimento e Meio Ambiente) - Universidade Federal do Piauí, Teresina/ PI, 2008.

WORLD HEALTH ORGANIZATION (WHO). International Statistical Classification of Diseases and Related Health Problems. 10th revision. [on line], 2007. Disponível em:<< http://www.who.int/classifications/ apps/icd/icd10online/.>> (Acesso em 26/04/2011).

ZSCHOCKE, S.; RABE, T.; STADEN, J. Plant part substitution - a way to conserve endangered madicinal plants? Journal of Ethnopharmacology, v. 71, p. 281 - 292. 2000. 